\title{
Early Versus Late Effort in Dynamic Agencies with Unverifiable Information
}

Jens Robert Schöndube, Faculty of Economics and Management, Otto-von-Guericke University Magdeburg,

E-mail: jens.schoendube@ww.uni-magdeburg.de

\begin{abstract}
In this paper we analyze a dynamic agency problem where contracting parties do not know the agent's future productivity at the beginning of the relationship. We consider a two-period model where both the agent and the principal observe the agent's second-period productivity at the end of the first period. This observation is assumed to be non-verifiable information. We compare long-term contracts with short-term contracts with respect to their suitability to motivate effort in both periods. On the one hand, short-term contracts allow for a better fine-tuning of second-period incentives as they can be aligned with the agent's second-period productivity. On the other hand, in short-term contracts first-period effort incentives might be distorted as contracts have to be sequentially optimal. Hence, the difference between long-term and short-term contracts is characterized by a trade-off between inducing effort in the first and in the second period. We analyze the determinants of this trade-off and demonstrate its implications for performance measurement and information system design.
\end{abstract}

Keywords: dynamic agency problem, limited commitment, unverifiable information, performance measurement

Manuscript received December 7, 2007, accepted by Rainer Niemann (Accounting) October 3, 2008.

\section{Introduction}

The agency-theoretic literature has spent an enormous amount of effort analyzing long-term incentive problems (e.g., Lambert 1983, Fudenberg, Holmström, and Milgrom 199o, Chiappori, Macho, Rey, and Salanie 1994, or Christensen, Feltham, and Şabac 2005). Two aspects are of particular relevance in this literature: The (dis-)ability of parties to commit to a long-term contract and the distinction between observability and verifiability of information. ${ }^{1}$ When contracting is complete in the sense that all jointly observable variables are verifiable, long-term commitment has proven to be valuable. Given complete contracts each anticipated future contract change can be included in the initial long-term contract such that there is no need to modify the contract subsequently. Rather, limited commitment may worsen the outcome as contracting parties are forced to act sequentially

${ }^{1}$ See Bolton (1990) for an overview. optimal, while with long-term commitment they can commit to strategies that are not sequentially optimal. Roughly stated, short-term contracting or renegotiation is ex ante efficient only if there is no difference between ex-ante optimality and ex-post optimality. ${ }^{2}$

For real incentive problems, however, it is reasonable to assume that contracting parties are better informed than, e.g., a court that would enforce the contract in the case of a dispute. ${ }^{3}$ Most transactions and relationships are very specific such that a court is not able to interpret data in the manner an insider would. In such a setting the complete contracting assumption is violated and the notion of a characteristic of the relationship being "observable but not verifiable" has been introduced into

\footnotetext{
2 Fudenberg, Holmström, and Milgrom (1990) and Chiappori, Macho, Rey, and Salanie (1994) developed criteria that ensure identity of ex-post optimality and ex-ante optimality in complete contracts.

3 See Hermalin and Katz (1991).
} 
the literature. If contracting parties jointly observe variables that are not verifiable the possibility of renegotiation or short-term contracting might improve the outcome of the relationship, as it allows to incorporate implicitly non-verifiable information into the contract. A very prominent analysis of this kind is Hermalin and Katz (1991) where the agent's effort is observable but not verifiable.

A general lesson from analyzing long-term incentive problems is that slight changes in the information structure may have substantial consequences for the outcome of the agency ${ }^{4}$ and therefore may lead to different recommendations for optimal performance management and information system design. In this sense, e.g., Lambert (2001) emphasizes the need to investigate long-term incentive problems especially related to commitment issues to attain a deeper understanding of the impact of performance measurement in dynamic agencies.

In this paper we model a long-term agency relationship that brings two of the issues mentioned before together. On the one hand, contracting parties observe non-verifiable information during the relationship which facilitates spot commitment as future effort incentives can be improved. On the other hand, short-term contracts may distort early effort incentives as they have to be sequentially optimal. Hence, the preferability of a long-term contract or spot contracting depends on the importance of early effort relative to late effort.

We consider a two-period agency relationship in which the contracting parties privately observe the agent's second-period productivity at the end of the first period. The idea underlying this assumption is that the manager's future contribution to both firm value and performance measures is uncertain ex ante but becomes more transparent by observing the production process over time.

Within this setting we analyze the trade-off between early and late effort motivation by comparing short-term contracts with long-term contracts. This trade-off is shown to be critically influenced by strategic effort and potential multi-tasking problems. Furthermore, the variance of the agent's productivity is an important factor; not due to risksharing considerations but by virtue of a costly effort allocation across different states of nature. In short-term contracts we further distinguish if

4 Compare e.g. Fudenberg and Tirole (1990) with Hermalin and Katz (1991). the agent's effort is unobservable or observable but not verifiable. ${ }^{5}$ We do so for two reasons: First, it allows us to clearly confine how the specific determinants of first- and second-period effort motivation vary with (small) changes in the information structure. Second, the analysis of observable but not-verifiable actions is applicable to a couple of real-world situations ${ }^{6}$ and itself generates interesting results, in particular a full separation of periods.

Having analyzed the trade-off between first- and second-period effort motivation we demonstrate implications for performance measurement and information system design. We first analyze the value of productivity information for the agency. It is well known ${ }^{7}$ that in strategic interactions (games) additional information may have negative value. It has been shown by Demski and Frimor (1999) and Indjejikian and Nanda (1999) amongst others that information rationing - for instance, via aggregation of information - might be beneficial in dynamic incentive problems. Most of the papers showing this effect are dealing in a complete contracting world where the only information available is the verifiable performance measures. In the model employed here, however, we investigate the value of an unverifiable signal in a dynamic setting. Not observing the signal may be beneficial as it may prevent contracting parties from taking second-period decisions that distort first-period decisions. In addition, in long-term contracts not observing the agent's productivity may be optimal to avoid an ex-ante uncontrollable random second-period action taken by the manager.

The accounting system of the firm can be interpreted as the information system providing the measures for the compensation contract with the manager. ${ }^{8}$ We apply our model to compare two different types of revenue recognition, the percentage of completion method and the completed

\footnotetext{
5 As in long-term contracts the principal cannot react on the observation of the agent's actions, we do not need to distinguish whether or not the agent's effort is observable.

6 Consider relationships where both contracting parties work close together such that the principal can directly observe which actions the agent has taken without being able to formally prove them. Furthermore, there might be a subjective performance measure that allows the principal directly to infer the agent's action. The literature on implicit contracts often presumes that the agent's effort itself is the subjective measure that can be implicitly contracted upon (see, e.g., Bull 1987).

7 For example see Demski (1988).

8 See Christensen and Demski (2003), chapter $11 \mathrm{ff}$.
} 
contract method, as different means to control the agent's effort in a long-term construction contract. In contrast to Arnegger and Hofmann (2007), who compare both methods under the full-commitment assumption, we are particularly interested in analyzing them under limited commitment in combination with unverifiable information. In a broader sense our analysis can be interpreted as comparing cash accounting to accrual accounting. In this aspect our paper is related to the literature on comparing accounting systems in dynamic agencies: Kwon (1989) considers a two-period setting with full commitment. The main emphasis of his paper is to analyze the trade-off between risk and incentives regarding the timing of information.

Reichelstein (2000) analyzes performance measures based on cash flows and on accruals (residual income). The objective is to implement incentive schemes that induce the agent to put effort into finding investment projects and then to realize only profitable projects. Wagenhofer (2003) considers a sequence of short-term contracts in a model where the agent's effort has long-term and short-term consequences. He analyzes optimal depreciation rules that induce the desired incentives by transferring part of the contribution of the longterm action in the period of choice.

Finally, our paper is related to the literature on the congruity of performance measures in multitask-models. In the standard multi-task model $^{9}$ the principal's objective (firm value) is not contractible and the manager's effort has to be allocated across different tasks. Specific multi-task models are analyzed by Baker (1992), Kopel (1998), and Bushman, Indjejikian, and Penno (200o). They analyze a oneshot full commitment problem with private predecision information. The agent privately observes his productivity after the contracting date. Baker and Kopel show that agency costs may occur even with risk-neutral parties if the principal cannot optimally allocate the agent's effort across different states of nature. Bushman, Indjejikian, and Penno analyze the delegation of decision rights. In a centralized regime the agent's effort is contractible but productivity is not observable, whereas in a decentralized system the agent privately observes his productivity but effort is non-contractible.

The rest of the paper is organized as follows: In

9 See Holmström and Milgrom (1991), Feltham and Xie (1994), and Datar, Cohen Kulp, and Lambert (2001). the next section we introduce the model. In Section 3 we conduct the equilibrium analysis for the three contracting regimes considered in this paper. Section 4 analyzes the determinants of the trade-off between early and late effort. In Section 5 we demonstrate implications for performance measurement and information system design and Section 6 summarizes.

\section{The model}

In this section we introduce the model. We use the most parsimonious model that allows to capture the relevant trade-offs between late and early effort motivation. Nonetheless, we are anxious to interpret the results in terms of a more general economic environment besides the specifics of the model. We consider a two-period agencyrelationship between a risk-neutral principal and a risk-neutral agent (manager), both having unlimited liability. The firm's lifetime exceeds the duration of the agency and the principal's firm value is not contractible. The latter assumption applies to non-public firms that will not be valuated at the capital market, or, in a non-valuation context, it is evident if the firm's output is realized only after the termination of the agency. We assume that non-contractibility goes along with non-congruity of financial measures. This means, that the agent's contribution to the financial measures of the two periods does not coincide with the contribution of his actions to firm value. ${ }^{10}$

The principal's information system reports the following performance measures $y_{t}$ at the end of period $t=1,2$

$$
\begin{aligned}
& y_{1}=v_{11} e_{11}+v_{12} e_{12}+\eta_{1} \\
& y_{2}=v_{21} e_{11}+\theta e_{2}+\eta_{2} .
\end{aligned}
$$

Here $\mathbf{e}_{1}^{\prime}=\left(e_{11}, e_{12}\right)$ are the manager's first-period actions and $e_{2}$ is his second-period effort. Actions are non-verifiable, but they might be observable. We assume that the manager has to perform two tasks in the first period: a strategic ${ }^{11}$ (long-term)

\footnotetext{
${ }^{10}$ Non-congruity captures the fact that a firm's future potential is represented by its financial measures with a time lag (see Sliwka 2002). The relevance of this problem is reflected by the rising attention that is devoted to non-financial components in compensation contracts (see Sliwka 2002 and Budde 2007).

11 See also Sliwka (2002) and Dutta and Reichelstein (2003) for an analysis of long-term and short-term contracts (or renegotiation-proof contracts, respectively) with strategic effort.
} 
action $e_{11}$ that influences the performance in both periods and an operational (short-term) action $e_{12}$ that only influences first-period performance. $\mathbf{v}_{1}=\left(v_{11}, v_{12}\right)^{\prime}$ is the (marginal) productivity vector of first-period effort in performance measure $y_{1}$ and $\mathbf{v}_{2}=\left(v_{21}, 0\right)^{\prime}$ is the productivity vector of $\mathbf{e}_{1}$ in performance measure $y_{2}$. We assume $\mathbf{v}_{1} \geq \mathbf{0}$, i.e. $\mathbf{v}_{1} \geqq \mathbf{0}$ but $\mathbf{v}_{1} \neq \mathbf{0}$, and $v_{21} \geq 0$ throughout the analysis. As allocating the agent's effort across several tasks in the second period does not create an interesting problem in our setting, we model second-period effort as a one-dimensional action $e_{2}$. The agent's productivity in the second period, $\theta$, is a random variable from the ex-ante perspective, continuously distributed on a subset of the positive real numbers. The realization of the random variable $\theta$ will be jointly observed by both parties at the end of period one; however, $\theta$ is assumed to be non-verifiable information such that the contracting parties cannot write an explicit contract on it. The additive noise terms $\eta_{1}$ and $\eta_{2}$ are independently distributed each with strictly positive density on $(-\infty, \infty)^{12}$ and $E\left(\eta_{1}\right)=E\left(\eta_{2}\right)=0$. $\eta_{1}$ and $\eta_{2}$ are also independently distributed of $\theta$. We restrict compensation contracts to be affinelinear ${ }^{13}$ functions of the performance measures. The compensation function of period $t$ is given by $S_{t}=s_{t} y_{t}+F_{t}$, with $F_{t}$ as a fixed payment and $s_{t}{ }^{14}$ as the incentive weight of period $t$. The agent's disutility from performing effort in pe$\operatorname{riod} 1$ is $C_{1}\left(\mathbf{e}_{1}\right)=\mathbf{e}_{1}^{\prime} \mathbf{e}_{1} / 2$ and for period 2 it is $C_{2}\left(e_{2}\right)=e_{2}^{2} / 2$. His reservation utility is set to zero in each period without loss of generality.

The principal's firm value is given by

$$
\pi=g_{11} e_{11}+g_{12} e_{12}+\gamma_{2} e_{2}+\eta_{\pi} .
$$

Here $g_{11}$ and $g_{12}$ are the marginal productivities of first-period actions $e_{11}$ and $e_{12}$ and $\gamma_{2}$ is the productivity of action $e_{2}$. Like $\theta \gamma_{2}$ is a random variable continuously distributed on some subset of $R^{+} . \theta$ and $\gamma_{2}$ have a joint distribution $f\left(\theta, \gamma_{2}\right)$ with stochastic independence $f\left(\theta, \gamma_{2}\right)=f_{\theta}(\theta) f_{\gamma_{2}}\left(\gamma_{2}\right)$ as a special case. The realization of $\gamma_{2}$ will never be

${ }_{12}$ This assumption ensures that even if $v_{21}$ is zero the observation of $\theta$ and $y_{2}$ does not reveal action $e_{2}$.

${ }^{13}$ Linear contracts are a usual assumption in models of performance measurement in agencies with risk-neutral parties, see for instance Baker (1992) and Budde (2007).

${ }^{14} \mathrm{We}$ do not restrict incentive weights to be defined on $[0,1]$. While this restriction is natural in a one-shot agency where the principal's outcome is contractible, with a non-contractible firm value it leads to corner solutions that are hard to interpret. detected by the parties; however, the observation of $\theta$ may lead to a revision of the distribution of $\gamma_{2}$. The assumption that $\theta$ is observed after the first period but $\gamma_{2}$ is not is driven by the idea that the influence of the agent's second-period action on the second-period performance measure is more precisely measurable than its effect on firm value. $\eta_{\pi}$ is a random variable distributed with strictly positive density on $(-\infty, \infty)$ with $E\left(\eta_{\pi}\right)=0 . \gamma_{2}$ and $\eta_{\pi}$ are independently distributed of all other random variables of the model. As argued above the contribution of the agent's actions to firm value does not coincide with the contribution of the actions to the sum of $y_{1}$ and $y_{2}$, i.e. the relations $g_{11}=v_{11}+v_{21}, g_{12}=v_{12}$, and $\gamma_{2}=\theta$ do not hold simultaneously.

If the principal offers a contract at the beginning of period $t$, the optimal offer depends on his information set at the beginning of period $t$. The principal's expected firm value given his information at the beginning of period 1 is

$$
E(\pi)=g_{11} e_{11}+g_{12} e_{12}+E\left(\gamma_{2} e_{2}(\theta)\right)
$$

and his expectation at the beginning of the second period given the observation of $y_{1}$ and $\theta$ and given his conjecture about the agent's first-period actions $\widehat{\mathbf{e}}_{1}$ (if effort is unobservable) is

$$
E\left(\pi \mid y_{1}, \theta, \widehat{e}_{1}\right)=g_{11} \widehat{e}_{11}+g_{12} \widehat{e}_{12}+E\left(\gamma_{2} \mid \theta\right) e_{2}(\theta) .
$$

If the principal can observe the agent's actions we remove the carets in (1). Since the manager knows $\theta$ at his second-period action choice we write $e_{2}(\theta)$. Notice that in contrast to the usual assumption the second-period firm value productivity is generally not stationary in this model. Expectations at the beginning of the relationship are $E\left(\gamma_{2}\right)$ and after the first period expectations are $E\left(\gamma_{2} \mid \theta\right)$.

The distinction between observable and unobservable effort is material only with regard to firstperiod actions. Whether the second-period action is observable to the principal or not does not matter as after the second-period action choice the game is effectively over. Although we model riskneutral contracting parties with unlimited liability due to multi-tasking there is still an interesting incentive problem present. Two assumptions are important in this respect: First, the agent has to allocate his effort across several tasks, and second, the principal's objective is not contractible. Given non-contractibility of firm value "selling the firm 
to the agent" is formally excluded as a solution to the incentive problem. ${ }^{15}$

Then, agency costs may occur even with riskneutral contracting parties if the agent's effort cannot be optimally controlled across his tasks via the performance measures. With the two assumptions of non-contractibility and multi-tasking the literature does not focus on the classical tradeoff between risk and incentives in the first place but has developed a tool to analyze the problem of inefficient allocation of effort due to distorted performance measurement. ${ }^{16}$ While most of the multi-tasking literature assumes a one-shot agency with full commitment, in this paper the multi-task problem is integrated into a dynamic incentive problem with unverifiable information.

\section{Equilibrium solutions}

In this section we derive the equilibrium solutions for the three contracting regimes to be compared in this paper: long-term contracts, short-term contracts with unobservable effort, and short-term contracts with observable effort. In long-term contracts with full commitment, by definition both contracting parties are forced to stay throughout the two contracting periods. In short-term contracts neither the principal nor the agent are committed to working together for the full length of the agency. Generally, the principal's strategy includes the possibility to hire a different agent for the second period. Following part of the literature ${ }^{17}$ in short-term contracts we exogenously restrict attention to equilibria where the principal wants the agent to work for him for the full duration of the agency. ${ }^{18}$ This restriction is justified if costs of hiring a new agent for the second period are sufficiently high.

\footnotetext{
${ }_{15}$ Literally, selling the firm to an agent should always be possible no matter whether firm value is contractible or not. However, from a practical perspective this is not an applicable solution to an incentive problem such that excluding it formally by assuming non-contractibility of the firm value is justified.

${ }^{16}$ See Holmström and Milgrom (1991), Feltham and Xie (1994), and Baker (2000).

17 See, e.g., Meyer and Vickers (1997), Indjejikian and Nanda (1999), and Feltham, Indjejikian, and Nanda (2006).

${ }^{18}$ The possibility to replace the agent at the end of the first period by a different agent is analyzed in Christensen and Feltham (2005), p. 559ff, and in Şabac (2007).
}

\subsection{Long-term contracts}

Here we assume that both parties can commit to a two-period relationship and to not renegotiating the initial long-term contract $S=\left(S_{1}, S_{2}\right)$. Longterm commitment is a strong assumption as it assumes contracting parties can stick to the initial contract at later dates even if it is no longer efficient. We interpret long-term commitment as a benchmark and by comparing it to contracting environments with limited commitment we try to identify under which circumstances it is optimal to seek commitment devices to approach the fullcommitment solution. In a long-term contract it is immaterial for the outcome of the game if the agent's actions are observable or not. Even if effort was observable, the principal cannot use this information as he is committed to not renegotiating the initial contract.

In the long-term commitment setting the specifics of the contract $S=\left(S_{1}, S_{2}\right)$ will be fixed at the beginning of the relationship. To solve for the optimal long-term contract we begin with analyzing the agent's second-period action choice. At the beginning of the second period the agent (as well as the principal) has observed his second-period performance productivity $\theta$. His optimal secondperiod action conditional on $\theta$ for a given contract $S=\left(S_{1}, S_{2}\right)$ is given by ${ }^{19}$

$$
\begin{aligned}
e_{2}(\theta) & =\operatorname{argmax}_{e_{2}^{\prime}} E\left(F_{2}+s_{2} y_{2} \mid \theta\right)-C_{2}\left(e_{2}^{\prime}\right) \\
& =\operatorname{argmax}_{e_{2}^{\prime}} F_{2}+s_{2} \theta e_{2}^{\prime}+s_{2} v_{21} e_{11}-\frac{\left(e_{2}^{\prime}\right)^{2}}{2} \\
& =s_{2} \theta .
\end{aligned}
$$

The agent's ex-ante expected payoff with contract $S$ and given $e_{2}(\theta)=s_{2} \theta$ is then given by

$$
\begin{aligned}
E\left(\Pi^{A}\right) & =E\left(F_{1}+s_{1} y_{1}+F_{2}+s_{2} y_{2}\left(e_{2}(\theta)\right)\right) \\
& -C_{1}\left(\mathbf{e}_{1}\right)-E\left[C_{2}\left(e_{2}(\theta)\right)\right] \\
& =F_{1}+s_{1}\left(v_{11} e_{11}+v_{12} e_{12}\right)+F_{2} \\
& +s_{2} v_{21} e_{11}+\frac{s_{2}^{2} E\left(\theta^{2}\right)}{2}-\frac{e_{11}^{2}}{2}-\frac{e_{12}^{2}}{2} .
\end{aligned}
$$

From the optimality condition $d E\left(\Pi^{A}\right) / d \mathbf{e}_{1}=0$ we derive the optimal first-period actions as

$$
\mathbf{e}_{1}=\left(s_{1} v_{11}+s_{2} v_{21}, s_{1} v_{12}\right)^{\prime}
$$

\footnotetext{
${ }^{19} \mathrm{As} y_{1}$ is independent of all other random variables we do not explicitly mention it in expressing conditional expectations in what follows.
} 
The optimal long-term contract is then the solution to the following optimization problem

$$
\begin{aligned}
& \max _{F_{1}, s_{1}, F_{2}, s_{2}} E\left(\pi-s_{1} y_{1}-F_{1}-s_{2} y_{2}-F_{2}\right) \\
& \text { s.t. } \\
& \mathbf{e}_{1}=\left(s_{1} v_{11}+s_{2} v_{21}, s_{1} v_{12}\right)^{\prime} \\
& e_{2}(\theta)=s_{2} \theta \\
& E\left(\Pi^{A}\right) \geq 0 .
\end{aligned}
$$

The principal maximizes the net value of the firm taking into account the participation constraint $\left(E\left(\Pi^{A}\right) \geq 0\right)$ and the incentive constraints for the actions in both periods.

Lemma 1: The optimal incentive weights $\left(s_{1}^{*}, s_{2}^{*}\right)$ and the principal's equilibrium payoff $\left(\Pi^{L}\right)$ in a long-term contract are given by ${ }^{20}$

$$
\begin{aligned}
s_{1}^{*} & =\frac{v_{21}^{2} g_{12} v_{12}+E\left(\theta^{2}\right)\left(g_{11} v_{11}+g_{12} v_{12}\right)}{E\left(\theta^{2}\right)\left(v_{11}^{2}+v_{12}^{2}\right)+v_{12}^{2} v_{21}^{2}}, \\
& -\frac{v_{11} v_{21} E\left(\gamma_{2} \theta\right)}{E\left(\theta^{2}\right)\left(v_{11}^{2}+v_{12}^{2}\right)+v_{12}^{2} v_{21}^{2}} \\
s_{2}^{*} & =\frac{E\left(\gamma_{2} \theta\right)\left(v_{11}^{2}+v_{12}^{2}\right)+v_{12}^{2} g_{11} v_{21}}{E\left(\theta^{2}\right)\left(v_{11}^{2}+v_{12}^{2}\right)+v_{12}^{2} v_{21}^{2}} \\
& -\frac{v_{21} v_{11} g_{12} v_{12}}{E\left(\theta^{2}\right)\left(v_{11}^{2}+v_{12}^{2}\right)+v_{12}^{2} v_{21}^{2}} \\
\Pi^{L} & =\frac{v_{21}^{2} v_{12}^{2}\left(g_{11}^{2}+g_{12}^{2}\right)}{2\left[E\left(\theta^{2}\right)\left(v_{11}^{2}+v_{12}^{2}\right)+v_{12}^{2} v_{21}^{2}\right]} \\
& +\frac{E\left(\theta^{2}\right)\left(v_{12} g_{12}+g_{11} v_{11}\right)^{2}}{2\left[E\left(\theta^{2}\right)\left(v_{11}^{2}+v_{12}^{2}\right)+v_{12}^{2} v_{21}^{2}\right]} \\
& +\frac{2 E\left(\gamma_{2} \theta\right) v_{21}\left(g_{11} v_{12}^{2}-g_{12} v_{11} v_{12}\right)}{2\left[E\left(\theta^{2}\right)\left(v_{11}^{2}+v_{12}^{2}\right)+v_{12}^{2} v_{21}^{2}\right]} \\
& +\frac{E\left(\gamma_{2} \theta\right)^{2}\left(v_{12}^{2}+v_{11}^{2}\right)}{2\left[E\left(\theta^{2}\right)\left(v_{11}^{2}+v_{12}^{2}\right)+v_{12}^{2} v_{21}^{2}\right]} .
\end{aligned}
$$

Proof. See Appendix.

\subsection{Short-term contracts}

\subsubsection{Unobservable effort}

Now we assume that the contracting parties have only limited commitment power such that they can only agree on short-term one-period contracts. At

${ }^{20}$ We suppressed the optimal fixed payments $F_{1}^{*}$ and $F_{2}^{*}$ in Lemma 1. They are crucial to ensuring that the agent's participation constraint is binding but do not affect incentives. As our focus is on incentive effects we waive presentation of explicit solutions for all fixed payments that do not influence incentives here and in the following sections. the beginning of the first period the principal offers the first-period contract $S_{1}$ and at the end of the first period (i.e. after $y_{1}$ and $\theta$ have been observed) the principal offers the second-period contract $S_{2}$. Christensen, Feltham, and Şabac (2003) have shown in a two-period agency with short-term contracts that there exists no equilibrium in which the agent stays for both periods if performance measures are correlated and the agent is not committed to stay for both periods. With correlation the optimal second-period contract depends on the principal's conjecture about the agent's first-period effort. Given the principal conjectures that the agent has chosen the first-period effort that is optimal if he stays for two periods, the agent has an incentive to "take the money and run" after the first period. Although in our model performance measures are not correlated, the same strategy for the agent shows to be optimal as first- and secondperiod measures are connected through strategic effort $e_{11}$. To sustain an equilibrium in which the agent stays for the full duration of the agency we assume "fair contracts"21 in combination with a commitment of the agent to stay for both periods. Fairness refers to a commitment of the principal to offer a second-period contract $S_{2}$ that meets the agent's second-period participation constraint given he has performed the desired (conjectured) first-period actions. Given fairness the agent can commit to stay for both periods without running the risk of being exploited by the principal in the second period.

Beginning with Baron and Besanko's (1987) investigation of a dynamic regulatory relationship, fair contracts have been (explicitly and implicitly) assumed in a number of contributions to the literature..$^{22}$ The use of fair contracts relies on the idea that a court can enforce fairness by reviewing the compensation contracts offered. ${ }^{23}$ If the principal was not forced to offer a fair contract at the beginning of the second period, fairness is ex-post inefficient and the agent would never commit to staying for both periods. Interestingly, Christensen, Feltham, and Şabac (2003) show in a LEN model the formal identity of fair short-term contracts and a long-term renegotiation-proof contract that

\footnotetext{
${ }^{21}$ See Baron and Besanko (1987) and Christensen, Feltham, and Şabac (2003).

${ }^{22}$ See Meyer (1995), Meyer and Vickers (1997), and Indjejikian and Nanda (1999).

${ }^{23}$ See Baron and Besanko (1987), p. 419.
} 
seems to be more accepted ${ }^{24}$ in the literature. As in our dynamic model contracting parties observe unverifiable information, no such equivalence can be shown. We employ fairness to preclude optimality of the "take the money and run" strategy by the agent presuming that fairness is enforceable by a court.

Given a second-period contract $S_{2}=F_{2}+s_{2} y_{2}$ the agent selects his second-period effort according to (2) as $e_{2}(\theta)=s_{2} \theta$. The agent accepts the contract only if his second-period payoff conditional on $\theta$ and $\mathbf{e}_{1}$ is at least zero.

$$
\begin{aligned}
E\left(F_{2}+s_{2} y_{2} \mid \theta, \mathbf{e}_{1}\right)-C_{2}\left(e_{2}(\theta)\right) & \geq 0 . \\
& \Leftrightarrow \\
F_{2}+s_{2}\left(v_{21} e_{11}+\theta e_{2}(\theta)\right)-\frac{e_{2}(\theta)^{2}}{2} & \geq 0 .
\end{aligned}
$$

The principal's optimal second-period contract offer given conjecture $\widehat{\mathbf{e}}_{1}$ is then characterized by the solution to the following optimization program:

$$
\begin{aligned}
& \max _{F_{2}, s_{2}} E\left(\pi \mid \theta, \widehat{\mathbf{e}}_{1}\right)-F_{2}-s_{2} E\left(y_{2} \mid \theta, \widehat{\mathbf{e}}_{1}\right) \\
& \text { s.t. } \\
& e_{2}(\theta)=s_{2} \theta \\
& E\left(F_{2}+s_{2} y_{2} \mid \theta, \widehat{\mathbf{e}}_{1}\right)-C_{2}\left(e_{2}(\theta)\right) \geq 0 .
\end{aligned}
$$

Since the principal designs the contract without having observed first-period effort we replaced $\mathbf{e}_{1}$ by the conjecture $\widehat{\mathbf{e}}_{1}$ within the participation constraint in program (4). Let $\mathbf{e}_{1}^{*}$ denote the conjectured first-period equilibrium action given the agent stays for both periods, then fairness means that the principal can commit ex ante to a secondperiod contract that fulfills

$E\left(F_{2}+s_{2} y_{2} \mid \theta, \mathbf{e}_{1}^{*}\right)-C_{2}\left(e_{2}(\theta)\right) \geq 0$.

Lemma 2: The optimal second-period contract given conjecture $\widehat{\mathbf{e}}_{1}$ is given by $s_{2}^{s *}=\frac{E\left(\gamma_{2} \mid \theta\right)}{\theta}$ and $F_{2}^{s *}=-\frac{E\left(\gamma_{2} \mid \theta\right)}{\theta} v_{21} \widehat{e}_{11}-\frac{1}{2} E\left(\gamma_{2} \mid \theta\right)^{2}$.

Proof. See Appendix.

Given the optimal second-period action $e_{2}(\theta)=$ $s_{2} \theta$ and the anticipated second-period contract $S_{2}^{s *}=\left(F_{2}^{s *}, s_{2}^{s *}\right)$ conditional on $\widehat{\mathbf{e}}_{1}$, we move to the first stage of the game to determine optimal first-period actions and the optimal first-period contract. The agent's expected surplus from the two-period relationship is given by

${ }^{24}$ See Christensen, Feltham, and Sabac (2003, p. 429), but also see the reply by Indjejikian and Nanda (2003, p. 440).
(5)

$$
\begin{aligned}
E\left(\Pi^{A}\right) & =E\left(F_{1}+s_{1} y_{1}+F_{2}^{s *}+s_{2}^{s *} y_{2}\right) \\
& -C_{1}\left(\mathbf{e}_{1}\right)-E\left[C_{2}\left(e_{2}(\theta)\right)\right] \\
& =F_{1}+s_{1}\left(v_{11} e_{11}+v_{12} e_{12}\right) \\
& +E\left(\frac{\gamma_{2}}{\theta}\right) v_{21}\left(e_{11}-\widehat{e}_{11}\right)-\frac{e_{11}^{2}+e_{12}^{2}}{2} .
\end{aligned}
$$

Maximizing this objective function for $e_{11}$ and $e_{12}$ yields the following optimal actions for a given incentive weight $s_{1}$ :

$$
\mathbf{e}_{1}=\left(s_{1} v_{11}+E\left(\frac{\gamma_{2}}{\theta}\right) v_{21} ; s_{1} v_{12}\right)^{\prime} .
$$

Then, the principal's problem in determining the optimal first-period contract is the following

$$
\begin{aligned}
& \max _{s_{1}, F_{1}} E(\pi)=g_{11} e_{11}+g_{12} e_{12}+E\left(\gamma_{2} e_{2}(\theta)\right) \\
& -E\left(F_{1}+s_{1} y_{1}+F_{2}^{s *}+s_{2}^{s *} y_{2}\right) \\
& \text { s.t. } \\
& \mathbf{e}_{1}=\left(s_{1} v_{11}+E\left(\frac{\gamma_{2}}{\theta}\right) v_{21} ; s_{1} v_{12}\right)^{\prime}
\end{aligned}
$$

$E\left(\Pi^{A}\right)=F_{1}+s_{1}\left(v_{11} e_{11}+v_{12} e_{12}\right)-\frac{e_{11}^{2}+e_{12}^{2}}{2} \geq 0$. Notice that in equilibrium, conjectures about $e_{11}$ are consistent with (7) such that the term

$E\left(\frac{\gamma_{2}}{\theta}\right) v_{21}\left(e_{11}-\widehat{e}_{11}\right)$ vanishes within the participation constraint. Given that the optimal secondperiod contract provides the agent with his secondperiod reservation utility of zero, his ex-ante expected total surplus $E\left(\Pi^{A}\right)$ equals exactly the expected surplus from the first contract. The optimal fixed payment $F_{1}$ will be chosen such that the participation constraint of program (8) is binding. The optimal incentive weight $s_{1}^{s *}$ for period one and the equilibrium payoff $\Pi^{S}$ of the principal are given in Lemma 3:

\section{Lemma $3^{25}$}

$s_{1}^{s *}=\frac{g_{11} v_{11}+g_{12} v_{12}-E\left(\frac{\gamma_{2}}{\theta}\right) v_{21} v_{11}}{v_{11}^{2}+v_{12}^{2}}$

$\Pi^{S}=\frac{\left(g_{11} v_{11}+g_{12} v_{12}\right)^{2}+2 E\left(\frac{\gamma_{2}}{\theta}\right) v_{21}\left(g_{11} v_{12}^{2}-g_{12} v_{12} v_{11}\right)}{2\left(v_{11}^{2}+v_{12}^{2}\right)}$

$-\frac{v_{12}^{2} v_{21}^{2}\left\{E\left(\frac{\gamma_{2}}{\theta}\right)\right\}^{2}}{2\left(v_{11}^{2}+v_{12}^{2}\right)}+\frac{1}{2} E\left\{E\left(\gamma_{2} \mid \theta\right)^{2}\right\}$.

Proof. See Appendix.

\subsubsection{Observable effort}

Whether the agent's actions are observable or not by the principal certainly depends on the terms of

\footnotetext{
${ }^{25}$ As the optimal first-period fixed payment does not influence the agent's incentives we omit it in Lemma 3 and in the following subsection, see also Footnote 20.
} 
the relationship. The assumption of observability of actions is justified if principal and agent work very closely together, if there exists a subjective measure that allows the principal to unambiguously infer the actions, or if the principal is able to implement a monitoring technology that perfectly reveals the agent's actions without serving as a proof from a juridical perspective. In a multiperiod incentive problem with spot contracts the observability of the agent's actions is crucial as the principal will use observed actions to fine-tune the contract for the next period.

When the principal can observe but not verify the agent's effort the only formal difference to the previous section is that the principal can condition the second-period contract on his observation of the first-period actions $\mathbf{e}_{1}$ instead of his conjecture $\widehat{\mathbf{e}}_{1}$. With observable effort we do not need to apply the fairness concept to sustain an equilibrium as the agent cannot "fool" the principal. According to Lemma 2, the optimal second-period contract $S_{2}^{o *}=\left(F_{2}^{o *}, s_{2}^{o *}\right)$ given observation $\mathbf{e}_{1}$ is given by $s_{2}^{o *}=s_{2}^{s *}=\frac{E\left(\gamma_{2} \mid \theta\right)}{\theta}$ and $F_{2}^{o *}=-\frac{E\left(\gamma_{2} \mid \theta\right)}{\theta} v_{21} e_{11}-\frac{1}{2} E\left(\gamma_{2} \mid \theta\right)^{2} .^{26}$

Compared to the analysis in the previous subsection, the term $E\left(\frac{\gamma_{2}}{\theta}\right) v_{21}\left(e_{11}-\widehat{e}_{11}\right)$ in the agent's first-period optimization problem disappears as he knows that the principal will offer a second-period contract that provides him exactly with his reservation utility in the second period for every action vector $\mathbf{e}_{1}$ he performed in period one. As a result, the effect of the agent's first-period strategic action $e_{11}$ on second-period performance measure $y_{2}$ does not affect his first-period action choice. Anticipating the optimal second-period contract, the agent cannot influence his expected second-period compensation via $\mathbf{e}_{1}$ and therefore in equilibrium the strategic effect of first-period effort disappears. Essentially, in equilibrium the observation of (firstperiod) effort leads to a perfect separation of both periods. The second-period performance measure $y_{2}$ is used to motivate the (ex post) optimal secondperiod action $e_{2}$ and the first-period measure $y_{1}$ is used to control $\mathbf{e}_{1}$. The principal's expected payoff from the second period is identical to the unobservable effort case and equals

${ }^{26}$ The fact that optimal second-period fixed payments in both short-term regimes, $F_{2}^{S *}$ and $F_{2}^{o *}$, are negative is due to the assumption of a second-period reservation utility of zero and does not imply that the agent generally has to make an upfront payment to the principal.
$Z_{2}^{*}=E\left(\gamma_{2} e_{2}(\theta)\right)-E\left(e_{2}(\theta)^{2}\right) / 2=$ $=E\left(\gamma_{2} \theta s_{2}^{*}\right)-E\left(\theta^{2} s_{2}^{* 2}\right) / 2=\frac{1}{2} E\left\{E\left(\gamma_{2} \mid \theta\right)^{2}\right\}$.

The principal's optimal expected payoff from the first period $\left(Z_{1}^{o *}\right)$ is the solution to the following optimization program, which characterizes a standard one-shot incentive problem where two actions $e_{11}$ and $e_{12}$ have to be aligned via the performance measure $y_{1}$ with firm value $\pi$ :

$$
\begin{aligned}
& \max _{s_{1}, F_{1}} g_{11} e_{11}+g_{12} e_{12}-F_{1}-s_{1}\left(v_{11} e_{11}+v_{12} e_{12}\right) \\
& \text { s.t. } \\
& \mathbf{e}_{1}^{\prime}=\left(s_{1} v_{11}, s_{1} v_{12}\right) \\
& F_{1}+s_{1}\left(v_{11} e_{11}+v_{12} e_{12}\right)-\frac{e_{11}^{2}}{2}-\frac{e_{12}^{2}}{2} \geq 0 .
\end{aligned}
$$

Lemma 4: The optimal incentive rate resulting from program (8) is $s_{1}^{o *}=\frac{g_{11} v_{11}+g_{12} v_{12}}{v_{11}^{2}+v_{12}^{2}}$, the principal's corresponding first-period surplus is $Z_{1}^{o *}=\frac{\left(g_{11} v_{11}+g_{12} v_{12}\right)^{2}}{2\left(v_{11}^{2}+v_{12}^{2}\right)}$, and his total surplus is $\Pi^{S o}=Z_{1}^{o *}+Z_{2}^{*}=\frac{\left(g_{11} v_{11}+g_{12} v_{12}\right)^{2}}{2\left(v_{11}^{2}+v_{12}^{2}\right)}+\frac{1}{2} E\left\{E\left(\gamma_{2} \mid \theta\right)^{2}\right\}$.

Proof. See Appendix.

\section{Analyzing the basic trade-off: Early vs. late effort motivation}

In this section we analyze the preferability of longor short-term contracts building on the analysis of the previous section. The general advantage of short-term contracts is that the contracting parties can use unverifiable information (here: the agent's true productivity or the observation of first-period effort) to fine-tune the optimal second-period contract while the general disadvantage is that they will agree on a second-period contract that is ex-post optimal and possibly destroys first-period incentives. In long-term contracts without renegotiation it is the other way around. The optimal contract is forward looking in the sense that it incorporates the effect of first-period effort on second-period performance, i.e. contracting parties can commit to second-period contracts that are ex-post inefficient. On the other hand, they cannot react on new (unverifiable) information. We study this tradeoff by comparing the three contracting regimes analyzed in the previous section. Which regime is preferred depends on the "importance" of the second-period effort relative to the first-period effort with respect to both, the agent's performance 
measures and firm value. In this section we investigate the determinants of this trade-off and in the next section we demonstrate implications for performance measurement and information system design.

We first analyze the problem of motivating efficient first-period effort in sequentially optimal contracts. As we do not consider risk-sharing problems the only difference in motivating effort in shortterm contracts compared with long-term contracts is that the sequentially optimal second-period contract possibly reduces the set of implementable first-period actions. In short-term contracts the second-period bonus coefficient will be optimized for the second-period effort alone while in longterm contracts it can be used to directly control first-period effort if there are long-term performance effects. The following proposition states a sufficient condition ${ }^{27}$ such that sequentially optimal contracts do not reduce the set of implementable first-period actions.

Proposition 1: If first-period effort productivities $\mathbf{v}_{1}$ and $\mathbf{v}_{2}$ are linearly dependent ex-ante efficient first-period actions can be motivated in sequentially optimal contracts.

Proof. From (3), (7), and (8) we know induced first-period effort in the three contracting regimes is given by $\mathbf{e}_{1}^{L}=\mathbf{v}_{1} s_{1}+\mathbf{v}_{2} s_{2}, \mathbf{e}_{1}^{S}=\mathbf{v}_{1} s_{1}+\mathbf{v}_{2} E\left(\frac{\gamma_{2}}{\theta}\right)$, and $\mathbf{e}_{1}^{S o}=\mathbf{v}_{1} s_{1}$. Let $\mathbf{e}_{1}^{L *}=\mathbf{v}_{1} s_{1}^{*}+\mathbf{v}_{2} s_{2}^{*}$ denote the ex-ante efficient first-period effort induced via the long-term contract. If $\mathbf{v}_{1}$ and $\mathbf{v}_{2}$ are linearly dependent, $\mathbf{e}_{1}^{L *}=\mathbf{v}_{1}\left(s_{1}^{*}+\lambda s_{2}^{*}\right), \lambda \neq 0$. In short-term contracts setting $s_{1}^{s *}=s_{1}^{*}+\lambda\left(s_{2}^{*}-E\left(\frac{\gamma_{2}}{\theta}\right)\right)$ and $s_{1}^{o *}=s_{1}^{*}+\lambda s_{2}^{*}$, respectively, induces the ex-ante efficient first-period effort $\mathbf{e}_{1}^{L *}$.

Recall that $\mathbf{v}_{1}=\left(v_{11}, v_{12}\right)^{\prime}$ and $\mathbf{v}_{2}=\left(v_{21}, 0\right)^{\prime}$ are the productivity vectors of effort $\mathbf{e}_{1}=\left(e_{11}, e_{12}\right)^{\prime}$ in the performance measures $y_{1}$ and $y_{2}$. By definition action $e_{12}$ has no long-term consequences and $e_{11}$ has long-term consequences if $v_{21}>0$. This modeling allows us to capture both, a potential multi-task problem as there are two tasks but only one measure in period 1 and possible long-term consequences of effort. Given this structure, we can interpret the algebraic result of proposition 1 as follows: a welfare loss in short-term contracts

${ }^{27}$ Compare Schöndube (2005) for a similar condition in a model with complete contracts. (relative to long-term contracting) requires strategic consequences of first-period effort as well as a multi-task-problem in period 1. Only if these two conditions occur simultaneously, $\mathbf{v}_{1}$ and $\mathbf{v}_{2}$ are linearly independent. Assume first that there are no strategic consequences, $v_{21}=0$, which implies linear dependency of $\mathbf{v}_{1}$ and $\mathbf{v}_{2}$. With $v_{21}=0$ firstperiod effort incentives are determined solely by the first-period performance $y_{1}$ which can be contracted on in an ex-ante optimal manner anyway. Even with strategic consequences of first-period effort, $v_{21}>0$, linear independence of $\mathbf{v}_{1}$ and $\mathbf{v}_{2}$ requires $v_{12}>0$. That means, besides the strategic effect of first-period effort, there must be more tasks than performance measures in period one (here: two tasks $e_{11}$ and $e_{12}$ and one measure $\left.y_{1}\right)^{28}$. For $v_{12}=0$ the only task in period one is $e_{11} \cdot e_{11}$ alone can always be optimally controlled by adapting $s_{1}$ in either regime. If there is a multi-task problem plus strategic effort in period 1 , however, ex-ante efficiency generally requires to use the second-period measure explicitly to control firstperiod effort which is impossible in short-term contracts.

The ex-ante efficiency condition in proposition 1 is sufficient but it is not necessary for implementing ex-ante efficient first-period actions in short-term contracts. Even with a constrained set of implementable actions due to sequentially optimal contracts the ex-ante efficient first-period actions might be implementable in some cases. These cases depend on the agent's firm value productivities as well as on the distribution of $\left(\gamma_{2}, \theta\right)$ and can only be interpreted case by case. The condition of proposition 1 , however, only depends on the characteristics of the performance measures and ensures that all first-period actions that can be motivated in long-term contracts can be motivated in short-term contracts as well.

Short-term contracts with observable and with unobservable effort always generate the same secondperiod incentives. The difference is with regard to first-period incentives. With observable effort both periods are perfectly separated in the sense that the two-period agency problem can be decomposed in two separate one-shot problems: The first-period effort will be motivated solely by $y_{1}$ and $e_{2}$ will

\footnotetext{
${ }^{28}$ Note that $v_{21}>0$ guarantees that task $e_{11}$ is non-trivially existent. Given $v_{21}>0$, the existence of a multi-task problem requires $v_{12}>0$.
} 
be induced via $y_{2}$. In contrast, with unobservable effort the agent takes the impact of his first-period effort on the second-period performance into account. For the condition given in proposition 1, however, short-term contracts with observable and unobservable effort generate identical first-period actions as there is either no strategic action or there is no multi-task problem in period one. Furthermore, as in long-term contracts second-period incentives cannot be based on the actual secondperiod productivity, they are weakly dominated under the condition of Proposition 1:

Corollary 1: Given that ex-ante efficient firstperiod actions can be implemented in sequentially optimal contracts, short-term contracts are (weakly) preferred to long-term contracts, i.e. $\Pi^{S}$ $=\Pi^{S o} \geq \Pi^{L}$.

Given that first-period incentives are the same, the advantage of short-term contracting is that contracting parties can use the observed productivity $\theta$ to fine-tune the characteristics of the secondperiod contract whereas in long-term contracts these characteristics must be determined based on prior beliefs on $\theta$. The next proposition identifies under which circumstances the ability to use the productivity $\theta$ to fine-tune second-period incentives in short-term contracts is worthless.

Proposition 2: Sequentially optimal second-period incentives are implementable in long-term contracts if and only if $E\left(\gamma_{2} \mid \theta\right)=c \cdot \theta$, where $c$ is a positive constant.

Proof. Sequentially optimal incentives are given by $s_{2}^{s *}=\frac{E\left(\gamma_{2} \mid \theta\right)}{\theta}$. $s_{2}^{s *}$ can be implemented in longterm contracts only if $s_{2}^{s *}$ does not depend on $\theta$ as contracting occurs before $\theta$ will be observed. $s_{2}^{*}$ is independent of $\theta$ if and only if $E\left(\gamma_{2} \mid \theta\right)=c \cdot \theta$. As $\gamma_{2}$ and $\theta$ can take only positive values, $c>0$.

Corollary 2: If $E\left(\gamma_{2} \mid \theta\right)=c \cdot \theta$, then $\Pi^{L} \geq \Pi^{S}$.

If the sequentially optimal incentive rate does not depend on $\theta$ the principal can motivate the same second-period effort in long-term contracts as in short-term contracts. This directly implies that the principal could replicate the outcome of shortterm contracts with unobservable effort by a longterm contract and therefore $\Pi^{L} \geq \Pi^{S}$. On the other hand, the equilibrium outcome of shortterm contracts with observable actions in general cannot be imitated by a long-term contract as the incentive constraints differ.

Combining Proposition 1 and Proposition 2 leads to:

Corollary 3: Given the conditions in Proposition 1 and Proposition 2 apply simultaneously, this results in: $\Pi^{S}=\Pi^{S o}=\Pi^{L}$.

The conditions in Proposition 1 and 2 ensure that the comparative advantages of either regime, longterm or short-term contracts, vanish. On the one hand, there is no need to use the second-period contract for first-period effort motivation (which would be possible in long-term contracts but not in short-term contracts) and, on the other hand, the sequentially optimal second-period incentive rate does not depend on the observed productivity such that sequentially optimal incentives are implementable in long-term contracts.

The next proposition emphasizes the impact of exante uncertainty about second-period firm value productivity $\left(\gamma_{2}\right)$ and performance measure productivity $(\theta)$ on the profitability of long-term and short-term contracts.

Proposition 3: Ceteris paribus, short-term contracts are getting (weakly) more attractive a) the higher the prior variance of $\theta$ and $b$ ) the higher the variance of $E\left(\gamma_{2} \mid \theta\right)$.

Proof. a) Writing $E\left(\theta^{2}\right)=E(\theta)^{2}+\operatorname{Var}(\theta), \Pi^{L}$ as defined in Lemma 1 is (weakly) decreasing in $\operatorname{Var}(\theta)$ and as $\Pi^{S}$ and $\Pi^{S o}$ do not depend on $\operatorname{Var}(\theta)$, short-term contracting becomes more attractive if $\operatorname{Var}(\theta)$ increases. b) Writing the term $E\left\{E\left(\gamma_{2} \mid \theta\right)^{2}\right\}$ in $\Pi^{S}$ and $\Pi^{S o}$ as $E\left(\gamma_{2}\right)^{2}+$ $\operatorname{Var}\left(E\left(\gamma_{2} \mid \theta\right)\right)$

$\operatorname{Var}\left(E\left(\gamma_{2} \mid \theta\right)\right)=E\left[\left(E\left(\gamma_{2} \mid \theta\right)-E\left(\gamma_{2}\right)\right)^{2}\right]$, both $\Pi^{S}$ and $\Pi^{S o}$ as defined in Lemma 3 and Lemma 4 are increasing in $\operatorname{Var}\left(E\left(\gamma_{2} \mid \theta\right)\right)$. As $\Pi^{L}$ does not depend on $\operatorname{Var}\left(E\left(\gamma_{2} \mid \theta\right)\right)$ the profitability of short-term contracts rises with $\operatorname{Var}\left(E\left(\gamma_{2} \mid \theta\right)\right)$.

In long-term contracts the principal fixes secondperiod incentives based on his prior information on $\theta$. The agent, however, selects his second-period action based on his observation $\theta$. As $\theta$ is random ex ante the agent's second-period effort choice is a random variable as well (ex ante). The higher the dispersion of $\theta$ the stronger the problem of motivating a second-period effort consistent with 
$\theta$ by an incentive rate independent of $\theta$. Similarly, the relative advantage generated by short-term contracts increases with

$$
\operatorname{Var}\left(E\left(\gamma_{2} \mid \theta\right)\right)=E\left[\left(E\left(\gamma_{2} \mid \theta\right)-E\left(\gamma_{2}\right)\right)^{2}\right]
$$

because with an increasing deviation from the prior mean the benefit of being able to set second-period incentives knowing the posterior mean of $\gamma_{2}$ conditional on $\theta$ becomes stronger.

In the last part of this section we analyze differences between short-term contracts with observable and with unobservable effort. As both regimes treat first-period effort differently there might be different recommendations for optimal performance measurement. We know from Proposition 1 that a necessary condition for both regimes to be different is strategic first-period effort in combination with a multi-task problem in period one. If effort is observable the long-term effect of first-period actions is cut in equilibrium and each period is separately controlled via its performance measure. With unobservable effort the long-term effect of the agent's first-period effort is incentive relevant; however, the second-period contract will be optimized only for the second-period action. The potential advantage of not observing the agent's action is that long-term effort effects show up in equilibrium. The disadvantage is that these effects cannot be controlled as the second-period incentive rate will be chosen sequentially optimal. If the misallocation of first-period effort due to the uncontrollable strategic effect becomes too strong the principal is better off to cut the long-term effect which corresponds to the observable effort case.

Proposition 4: Assume the condition in Proposition 1 does not apply:

a) If the first-period performance measure $y_{1}$ is perfectly congruent to $\pi$ w.r.t. $\mathbf{e}_{1}$, i.e. $g_{11} / g_{12}=$ $v_{11} / v_{12}$, observation of actions is strictly advantageous, $\Pi^{S o}>\Pi^{S}$.

b) If $y_{1}$ is not congruent to $\pi$ w.r.t. $\mathbf{e}_{1}$, then

b1) $\Pi^{S o}-\Pi^{S}$ is decreasing in $g_{11}$ and if $g_{11}$ becomes sufficiently high, $\Pi^{\text {So }}<\Pi^{S}$.

b2) If the long-term incentive component of unobservable first-period effort, $E\left(\frac{\gamma_{2}}{\theta}\right) v_{21}$, is suffciently strong, $\Pi^{S o}>\Pi^{S}$.
Proof. From Lemma 3 and Lemma 4

(9)

$$
\begin{aligned}
& \Pi^{S o}-\Pi^{S}=\frac{v_{12} v_{21} E\left(\frac{\gamma_{2}}{\theta}\right)}{2\left(v_{11}^{2}+v_{12}^{2}\right)} \\
& \times\left[2 g_{12} v_{11}-2 g_{11} v_{12}+v_{21} v_{12} E\left(\frac{\gamma_{2}}{\theta}\right)\right] .
\end{aligned}
$$

By assumption: $\mathbf{v}_{1}$ and $\mathbf{v}_{2}$ are linearly independent.

a) For $\frac{g_{11}}{g_{12}}=\frac{v_{11}}{v_{12}}, \Pi^{S o}-\Pi^{S}=\frac{\left[v_{12} v_{21} E\left(\frac{\gamma_{2}}{o}\right)\right]^{2}}{2\left(v_{11}^{2}+v_{12}^{2}\right)}>0$. b1) $\partial\left(\Pi^{S o}-\Pi^{S}\right) / \partial g_{11}=\frac{-v_{12}^{2} v_{21} E\left(\frac{\gamma 2}{\theta}\right)}{v_{11}^{2}+v_{12}^{2}}<0$ and as can be easily seen from (9) if $g_{11}$ is sufficiently high (holding the other parameters constant) $\Pi^{S o}<\Pi^{S}$. b2) The strategic effect of firstperiod effort is measured by $E\left(s_{2}^{s *}\right) v_{21}$ if effort is unobservable, with $E\left(s_{2}^{s *}\right)=E\left(\frac{\gamma_{2}}{\theta}\right)$.

From (9), if $v_{21} E\left(\frac{\gamma_{2}}{\theta}\right)$ becomes sufficiently high $\Pi^{S o}-\Pi^{S}>0$.

Congruity of a performance measure with respect to an effort vector as defined in Feltham and Xie (1994) is a necessary condition for the first-best effort being implementable through a performance measure. In our model the first-best effort in period $\mathbf{1}$ is $\mathbf{e}_{1}^{f^{\prime \prime} B}=\left(g_{11}, g_{12}\right)^{\prime}$. Ignoring the second period for the moment, first-best effort can be only induced via performance measure $y_{1}$ alone, if the quotient of marginal firm value products $g_{11} / g_{12}$ is equal to the quotient of marginal performance products of $y_{1}, v_{11} / v_{12}$. In this case, by setting the first-period incentive weight to $s_{1}=\frac{g_{11}}{v_{11}}\left(=\frac{g_{12}}{v_{12}}\right)$ the first-best effort $\mathbf{e}_{1}^{F B}$ can be induced in short-term contracts with observable effort as there is no strategic effect in equilibrium. With non-observable effort, however, action $e_{11}=s_{1} v_{11}+E\left(\frac{\gamma_{2}}{\theta}\right) v_{21}$ is influenced by the long-term component $E\left(\frac{\gamma_{2}}{\theta}\right) v_{21}>0$ such that it is never possible to induce $\mathbf{e}_{1}^{F B}$ and a welfare loss relative to the observable effort case occurs. If $y_{1}$ is not congruent to $\pi$ w.r.t. $\mathbf{e}_{1}$ not observing first-period effort becomes more advantageous if the firm value productivity $g_{11}$ of $e_{11}$ is increasing. Notice that, holding all other parameters constant, with $g_{11}$ increasing the importance of task $e_{11}$ relative to $e_{12}$ increases. With observable effort, both tasks will be determined solely by the first-period incentive rate $s_{1}$ while with unobservable effort task $e_{11}$ is also motivated by the strategic term $E\left(\frac{\gamma_{2}}{\theta}\right) v_{21}$. As the importance of action $e_{11}$ increases, measured by $g_{11}$, using the strategic performance effect becomes -although not controllable ex ante -more valuable. By a similar argument, ceteris paribus, 
if the strategic effect $E\left(\frac{\gamma_{2}}{\theta}\right) v_{21}$ is very strong the discrepancy between induced first-period actions $e_{11}$ and $e_{12}$ becomes inefficiently high such that the principal prefers an environment where no strategic effect is present: this corresponds to the case where effort is observable.

\section{Implications for performance measurement and information system design}

Based on the results derived before in this section we demonstrate implications for performance measurement and information system design. First, we analyze the value of unverifiable information in our model. In the agency-theoretic literature much effort has been made to analyze the value of additional information for the outcome of an agency (e.g., see Holmström's (1979) famous informativeness result). While most of the literature focuses on the value of contractible information we investigate if it is optimal for the principal to install an information system that reports unverifiable productivity information. Second, we interpret our setting as one in which a manager works on a long-term construction contract and we specify the information system defined in Section 2 as representing either the completed contract method or the percentage of completion method of revenue recognition. We compare both accounting regimes of revenue recognition regarding their suitability to induce early and late effort in long- and short-term contracts.

\subsection{Value of unverifiable information $\theta$}

Until now we assumed that the principal's information system unverifiably reports the productivity $\theta$ at the end of the first period. In this section, we analyze whether it is indeed optimal for the firm to install an information system that reports $\theta$. If the principal's information system does not show $\theta$ the agent selects his second-period action based on his prior belief on $\theta$, (similar to (2)) $e_{2}=s_{2} E(\theta)$. Furthermore, in short-term contracts if the information system does not report $\theta$ the principal sets sequentially optimal second-period incentives based on the joint prior distribution of $\left(\theta, \gamma_{2}\right)$. The following proposition provides elementary conditions for the information $\theta$ having positive or negative value in different contracting regimes.

\section{Proposition 5:}

a) In every contracting regime: If the conditions of Proposition 1 and Proposition 2 apply simultaneously, observing $\theta$ is always strictly beneficial.

b) In short-term contracts with observable effort observing $\theta$ can never be harmful.

c) Assume the conditions of Proposition 1 and Proposition 2 do not apply simultaneously:

c1) In long-term contracts: Observing $\theta$ has negative value if $\theta$ and $\gamma_{2}$ are independently distributed.

c2) In short-term contracts with unobservable effort: Observing $\theta$ has negative value if the following two conditions apply simultaneously: 1) $\theta$ and $\gamma_{2}$ are independently distributed and 2) the relative productivity of first-period actions in performance measure $y_{1}$ exceeds the relative productivity of these actions in firm value $\pi$, $v_{11} / v_{12}>g_{11} / g_{12}$.

\section{Proof. See Appendix.}

From Corollary 3 we know that under the conditions of Propositions 1 and 2 the three different contracting regimes are equivalent and generate exactly the same surplus for the agency. Furthermore, the conditions ensure that the observation of $\theta$ has no negative effect on first-period effort (Prop. 1) and at the same time observing $\theta$ is strictly beneficial with respect to second-period effort (Prop. 2 implies that equilibrium effort $e_{2}$ varies with $\theta, e_{2}=c \theta$ ). In short-term contracts the secondperiod incentive effect of observing $\theta$ can never have negative value. As in short-term contracts with observable effort both periods are perfectly separated, there exist no negative effects from the second-period use of $\theta$ on first-period effort such that observing $\theta$ is always weakly beneficial.

If $\theta$ is reported in long-term contracts the agent is induced to select a second-period action that depends on $\theta, e_{2}=s_{2}^{*} \theta$. This is valuable if $\theta$ is closely related to firm value productivity $\gamma_{2}$. If $\theta$ is not related to firm value, however, the variation of $e_{2}$ in $\theta$ is costly for the firm and the principal does better without observing the signal. Here, not related means that $\gamma_{2}$ and $\theta$ are independently distributed. In this case, the observation of $\theta$ does not help to direct the second-period action towards firm value. Rather, as the agent selects $e_{2}=s_{2}^{*} \theta$ the induced action is a costly random variable from the ex-ante perspective. Due to the agent's convex 
cost of effort it can never be optimal ${ }^{29}$ to induce different action levels across different realizations of performance productivities that are independent of the firm value (the proof follows directly from Jensen's inequality). Hence, with independent productivities $\theta$ and $\gamma_{2}$ an information system that does not reveal $\theta$ dominates an information system that reports $\theta$ in long-term contracts.

In short-term contracts the agent not only chooses his action conditional on $\theta$ but also the principal uses $\theta$ to align second-period incentives with firm value. If effort is unobservable first-period incentives are influenced by the second-period incentive rate if $v_{21}>0$. In this case not observing the productivity might be beneficial to avoid toostrong distortions in first-period effort. Assume $\theta$ and $\gamma_{2}$ are independently distributed. Given independence, observing $\theta$ does not influence secondperiod incentives, the induced second-period action is $e_{2}=E\left(\gamma_{2}\right)$ with and without observing $\theta$. The only difference is that with observable $\theta e_{2}=$ $s_{2} \theta=E\left(\gamma_{2}\right)$ is motivated via $s_{2}=\frac{E\left(\gamma_{2}\right)}{\theta}$ whereas the corresponding bonus coefficient without observing $\theta\left(e_{2}=s_{2} E(\theta)\right)$ is $s_{2}=\frac{E\left(\gamma_{2}\right)}{E(\theta)}$. Induced first-period strategic action $e_{11}=s_{1} v_{11}+E\left(s_{2}\right) v_{21}$ is in the first case $e_{11}=s_{1} v_{11}+E\left(\gamma_{2}\right) E\left(\frac{1}{\theta}\right) v_{21}$ and in the latter case it is $e_{11}=s_{1} v_{11}+\frac{E\left(\gamma_{2}\right)}{E(\theta)} v_{21}$, while the operational action is always $e_{12}=s_{1} v_{12}$. Since $E\left(\frac{1}{\theta}\right)>\frac{1}{E(\theta)}$ the induced strategic action with observable $\theta$ is always higher than without observing $\theta$. If the relation of first-period firm value productivities $g_{11} / g_{12}$ is less than the corresponding relation of performance productivities in $y_{1}$, $v_{11} / v_{12}$, the induced relation $e_{11} / e_{12}$ of first-period actions via $s_{1}$ alone, $v_{11} / v_{12}$, is already too high from the principal's view. Now, the optimal relation is further distorted by the long-term incentive effect $E\left(s_{2}\right) v_{21}$. As $E\left(s_{2}\right) v_{21}$ is always lower if $\theta$ is not observed an information system not reporting $\theta$ is preferred if $g_{11} / g_{12}<v_{11} / v_{12}$.

The general lesson from Proposition 5 is that observing the manager's productivity in a dynamic agency need not be beneficial for the outcome of the relationship. The value of unverifiably observing the agent's productivity in short-term contracts depends on whether the gains from possibly improved second-period incentives offset the first-

${ }^{29}$ A similar effect arises in Baker's (1992) private pre-decision information model. period incentive effect. The second-period incentive effect of $\theta$ cannot be negative. In short-term contracts with observable effort the first-period incentive effect of $\theta$ vanishes. With unobservable effort it might create costly misallocations of firstperiod actions such that the overall effect of observing $\theta$ can become negative. In long-term contracts even the second-period effect from observing $\theta$ can become negative as the principal cannot respond to the observation of $\theta$ such that induced $e_{2}$ may become a costly random variable from the ex-ante perspective.

In the literature the value of information in agencies has been analyzed for different assumptions on the information's character, its timing, and the dynamics of the agency. It is well known that in a static one-shot agency additional contractible expost information can never have negative value as the principal can always ignore it in the optimal contract. Holmström (1979) shows that an additional signal is valuable only if it is informative. If additional contractible information is observed, however, before the agent chooses his action the value of observing the signal may become negative. ${ }^{30}$ The problem with this kind of pre-decision information is that it cannot be ignored anymore as the agent chooses his action conditional on the signal which possibly makes inducing the desired action more costly. A similar effect arises in the long-term commitment setting in our model (see part $\mathrm{c} 1$ of Proposition 5). The agent chooses his second-period action depending on $\theta$ which becomes costly for the principal if $\theta$ is not related with firm value. The difference of our approach to the previous literature is that as $\theta$ is not verifiable the principal cannot directly control this effect via contracting upon $\theta$.

The results of Proposition 5 are also related to the literature that shows that in agencies with limited commitment information rationing may be optimal. Focussing on contractible information, Hofmann (2005) shows that the value of interim reports may become negative and Indjejikian and Nanda (1999) stress that aggregation of information may be optimal to mitigate the ratchet-effect. In Demski and Frimor (1999) and in Christensen,

${ }^{30}$ See Christensen and Demski (2003), chapter 13. A similar effect has been shown in a double moral hazard relationship, where also the principal takes some productive decision, see Arya, Glover, and Sivaramakrishnan (1997). 
Demski, and Frimor (2002) it may be optimal for the principal to induce earnings management by the agent to ration information. The positive effect of information rationing stems from the principal's desire to discipline his ex-post optimal behavior. Less detailed (interim) information biases the second-period incentive problem which in turn leads to less distorted first-period incentives. A related result is characterized in Proposition 5, part c2, for short-term contracts with unobservable effort for non-verifiable information $\theta$. The effect of the second-period bonus coefficient on first-period effort makes the principal better off without observing $\theta$.

While the literature discussed above analyzed the value of contractible information, the investigation of the value of unverifiable information is rare in the agency-theoretic literature on performance measurement. ${ }^{31}$ Hermalin and Katz (1991) and Gigler and Hemmer (2004) consider a one-period agency where renegotiation takes place before the realization of the outcome but after the agent's action choice. After the agent has exerted effort but before the renegotiation stage an unverifiable signal is observed. Renegotiation turns out to be beneficial as it implicitly allows for contracting on the unverifiable signal. Their results differ from our paper as in their setting the unverifiable signal in equilibrium appears like an additional ex-post performance measure such that there can never be any negative distortions with respect to (early) effort.

\subsection{Revenue recognition: percentage of completion method versus completed contract method}

In this section we use the information system introduced in Section 2 to investigate the incentive effects related to two accounting regimes of revenue recognition: the percentage of completion method and the completed contract method. Under the completed contract method revenues are recognized when the contract is fully completed. Under the percentage of completion method revenues are allocated over periods according to the

${ }^{31}$ Here, I do not account for the mechanism design literature that has shown that problems with unverifiable information can be solved by revelation mechanisms (Maskin 1999, Moore and Repullo 1988). See Hermalin and Katz (1991) for a criticism on the use of revelation mechanisms to make unverifiable information verifiable. percentage of completion of the particular contract. By specifying the productivity vectors $\mathbf{v}_{1}$ and $\mathbf{v}_{2}$ of the performance measures $y_{1}$ and $y_{2}$ defined in Section 2 appropriately we distinguish between the two revenue recognition methods as follows:

\section{Percentage of Completion:}

$$
\begin{aligned}
& y_{1}=(v+a) e_{11}+v_{12} e_{12}+\eta_{1} \\
& y_{2}=\theta e_{2}+\eta_{2} .
\end{aligned}
$$

Completed Contract:

$$
\begin{aligned}
& y_{1}=v e_{11}+v_{12} e_{12}+\eta_{1} \\
& y_{2}=a e_{11}+\theta e_{2}+\eta_{2} \\
& v, a \geq 0
\end{aligned}
$$

In the terminology of the information system introduced in Section 2 we have $v_{11}=(v+a)$ and $v_{21}=0$ under the percentage of completion method, and $v_{11}=v$ and $v_{21}=a$ under the completed contract method, i.e. the total marginal product of $\mathbf{e}_{1}$ is equal in both systems but the timing differs. To add intuition to the two information systems defined in (10) consider a two-period construction contract with effort $e_{11}$ in period 1 and $e_{2}$ in period 2. The expected payment from the contract at the end of period 2 is $a e_{11}+\theta e_{2}$; the estimated fraction completed at the end of the first period is $a e_{11} \cdot v e_{11}$ and $v_{12} e_{12}$ are cash flows related to different projects besides the construction contract; they are realized in period one under both systems. The revenue from the construction contract at the end of the first period under the percentage of completion method is noisily measured as $a e_{11}+\eta_{a}$ with $\eta_{a}$ being a random variable distributed on $(-\infty, \infty) \cdot \eta_{a}$ is not correlated with other random variables of the model and has $E\left(\eta_{a}\right)=0$. Due to estimation errors noise in the measurement of the accrual is prevalent. ${ }^{32}$ The accrual will be estimated by the firm's accountant. Though both contracting parties can observe the accrual, it is non-verifiable and cannot be used as a separate performance measure. It should be noticed that both systems of revenue recognition characterized in (10) and the assumption on the accrual are consistent with the information system introduced in Section 2. Under each method there is exactly one performance measure reported in each period. Formally, both information systems

\footnotetext{
${ }^{32}$ Compare also Kwon (1989).
} 
differ only in the way the total marginal contribution of action $e_{11}$ is allocated to the two periods. The fact that the accrual is noisily measured is irrelevant as both contracting parties are risk neutral. Furthermore, the noise term $\eta_{a}$ will be formally absorbed by the random variable $\eta_{1}$ under the percentage of completion method such that no reformulation of the information system defined in Section 2 is needed. ${ }^{33}$ In a wider interpretation the model can be regarded as representing either cash accounting (completed contract method) or accrual accounting (percentage of completion method).

If the duration of the agency were equal to the firm's lifetime the contribution of the agent's actions to the firm's cash flows should be equal to their contribution to firm value. As argued at the beginning of Section 2, however, the firm's lifetime exceeds $t=2$. In such a setting cash-flows typically do not adequately capture the influence of the agent's actions on the firm's future prospects. To give an example that extends the construction contract story, assume that higher effort $e_{11}$ and $e_{2}$ implies a higher project quality. High quality is not only associated with a higher expected return but also with an increase in the probability that the firm can attain a similar job in the future $t>2$. Naturally, these future prospects of the firm are not captured by the cash-flows and hence the contribution of $e_{11}$ and $e_{2}$ to firm value is higher than to the cash-flows of period 1 and period 2 .

Our objective is to derive conditions for the dominance of one or the other system and to clarify the incentive effects emerging under both methods under different contracting environments. If

\footnotetext{
${ }^{33}$ Consider the completed contract method with noise $\eta_{1}$ in period 1 and $\eta_{2}$ in period 2. Under the percentage of completion method $a e_{11}+\eta_{a}$ will be measured at the end of period $\mathbf{1}$ and becomes an integral part of the first-period performance measure $y_{1}$. Compared to the completed contract method the noise terms under percentage of completion should be different. Specifically, based on the noise terms defined under the completed contract method, total noise of first-period earnings should be $\eta_{1}+\eta_{a}$. Define $\eta_{1}^{\prime}=\eta_{1}+\eta_{a}$. Also, the secondperiod noise term under the percentage of completion method, denote it $\eta_{2}^{\prime}$, should deviate from $\eta_{2}$ (without additional structure nothing can be said about the relation of $\eta_{2}$ and $\eta_{2}^{\prime}$ but we assume here that $\left.E\left(\eta_{0}^{\prime}\right)=0\right)$. Formally, then we have noise terms $\left(\eta_{1}, \eta_{2}\right)$ under the completed contract method and $\left(\eta_{1}^{\prime}, \eta_{2}^{\prime}\right)$ under the percentage of completion method. As all noise terms have mean zero and since other characteristics of the noise terms' distributions are irrelevant with risk-neutral contracting parties, we do not formally distinguish between $\left(\eta_{1}, \eta_{2}\right)$ and $\left(\eta_{1}^{\prime}, \eta_{2}^{\prime}\right)$ in (10) and the subsequent analysis.
}

the accrual is zero $(a=0)$ both methods are equivalent by definition. Furthermore, both methods must be equivalent in all contracting environments if $v_{12}=0$ as then there is only one action in period 1 that can always be optimally motivated by the first-period incentive rate. In fact, $v_{12}=0$ and/or $a=0$ ensure for both systems that the ex-ante efficiency condition of Proposition 1 holds. To exclude trivial cases we assume this condition does not apply in what follows.

Analyzing long-term contracts first, we face a contracting problem where the incentive contract is fixed at $t=0$ and where the agent's action choices are given by (compare also (3))

$$
\left.\begin{array}{l}
e_{11}=s_{1}(v+a) \\
e_{12}=s_{1} v_{12} \\
e_{2}=s_{2} \theta \\
e_{11}=s_{1} v+s_{2} a \\
e_{12}=s_{1} v_{12} \\
e_{2}=s_{2} \theta
\end{array}\right\} \text { percentage of completion method }
$$

In short-term contracts the second-period incentive rate will be chosen sequentially optimal, $s_{2}=$ $\frac{E\left(\gamma_{2} \mid \theta\right)}{\theta}$, so that the induced second-period effort is independent of the type of revenue recognition. The part of the principal's surplus that is related to the second-period action is $E\left(\gamma_{2} e_{2}-\frac{e_{2}^{2}}{2}\right)$ for both methods. Hence, when comparing both methods in short-term contracts we can without loss of generality compare the first-period effects. If the agent's effort is not observable the manager's incentive compatibility conditions for $\mathbf{e}_{1}$ are given by (compare section 3.2.1, (6))

$$
\left.\begin{array}{l}
e_{11}=s_{1}(v+a) \\
e_{12}=s_{1} v_{12} \\
e_{11}=s_{1} v+E\left(\frac{\gamma_{2}}{\forall}\right) a \\
e_{12}=s_{1} v_{12}
\end{array}\right\} \text { percentage of completion method }
$$

With observable actions the agent's first-period incentives in short- term contracts are given by

$$
\left.\begin{array}{l}
e_{11}=s_{1}(v+a) \\
e_{12}=s_{1} v_{12} \\
e_{11}=s_{1} v \\
e_{12}=s_{1} v_{12}
\end{array}\right\} \text { percentage of completion method }
$$

As discussed in Section 3.2.2, long-term effects of effort are eliminated in short-term contracts with 
observable effort. As under the percentage of completion method long-term effects are drawn into the first period the agent's incentives are the same as in the unobservable action setting. Furthermore, with observable effort the surplus generated under the completed contract method is independent of the accrual component $a$ as long-term effects vanish.

\section{Proposition 6:}

a) For all contracting regimes: If the operational action $e_{12}$ is sufficiently valuable, the completed contract method dominates the percentage of completion method.

b) In long-term contracts and in short-term contracts with unobservable effort: If the secondperiod action $e_{2}$ is sufficiently valuable, the percentage of completion method dominates the completed contract method.

c) In short-term contracts: If the strategic action $e_{11}$ is sufficiently valuable, the percentage of completion method dominates the completed contract method.

\section{Proof. See Appendix.}

If the operational action $e_{12}$ is very important, particularly compared to the strategic action $e_{11}$, then the principal would like to differentiate between both first-period actions via the incentive system. Under the percentage of completion method all financial consequences of first-period actions are measured in period one. Hence, both firstperiod actions are exclusively motivated by the first-period incentive weight such that the relation between both actions, the quotient $e_{11} / e_{12}$, is fixed. Under the completed contract method, however, the project's revenue due to action $e_{11}$ is measured in period two such that it is possible to set strong incentives for the operational action $e_{12}$ via high $s_{1}$ without increasing the strategic action $e_{11}$ proportionally. ${ }^{34}$ If the second-period action $e_{2}$ is sufficiently valuable it is the other way around. Except for short-term contracts with observable actions the percentage of completion method is superior to the completed contract method. If rev-

\footnotetext{
34 In short-term contracts with observable effort, the long-term effect is cut. Here, the completed contract method dominates the percentage of completion method if $e_{12}$ is extremely valuable as the marginal contribution of action $e_{11}$ in $y_{1}$ is lower than under the percentage of completion method.
}

enues are recognized depending on the percentage of completion the second-period measure only depends on second-period effort. Hence, the principal can set high-powered second-period incentives without influencing first-period actions which explains the dominance for that method here. As in short-term contracts with observable actions both periods are perfectly separated, the second-period action does not influence the comparison of both methods.

If the strategic action $e_{11}$ is sufficiently valuable the percentage of completion method dominates the completed contract method in short-term contracts. The reason is that in short-term contracts the second-period effect of task $e_{11}$ either cannot be controlled ex ante optimally (unobservable effort) or it is simply lost (observable effort) under the completed contract method. In contrast, under the percentage of completion method all effects of the task $e_{11}$ will be measured in the first period such that it can be controlled ex ante optimally.

\section{Conclusion}

In this paper we analyzed a dynamic agency relationship where contracting parties observe the agent's second-period productivity at the end of the first period. Firm value is not contractible such that effort incentives must be motivated via a performance measurement system. The agent's second-period productivity was assumed to be non-verifiable information. We considered three different contracting regimes: long-term full-commitment contracts, short-term contracts with observable (but not verifiable) effort and short-term contracts with unobservable actions. In long-term contracts the principal can commit to secondperiod incentives that are not ex-post optimal but he cannot respond to the observation of the agent's productivity. In short-term contracts the principal can always use the productivity information to fine-tune second-period incentives; however, the sequentially optimal second-period contract might harm first-period effort incentives. We determined the equilibrium solution for each contracting regime and based on these results we analyzed the trade-off of motivating first- and secondperiod effort both between and within the three regimes.

We first showed that if there is neither a multitask-problem in period 1 nor long-term effects of 
first-period effort, then it is always possible to induce the ex-ante efficient first-period actions in short-term contracts. We then derived that the sequentially optimal second-period incentive rate can be implemented in long-term contracts only if the posterior mean of second-period firm value productivity is a linear function of the observed productivity. Furthermore, we analyzed the influence of the prior variance of the agent's productivity. An increasing variance makes short-term contracts more profitable relative to long-term contracts as with increasing dispersion it gets more difficult to control the desired second-period action without knowing its productivity in long-term contracts.

The differences between short-term contracts with observable and with unobservable effort are as follows: If the principal observes the agent's firstperiod effort, he offers a second-period contract that exactly meets the agent's second-period reservation utility given the observed first-period actions. Hence, in equilibrium the second-period compensation does not create incentives for the first-period action choice even if there are strategic (i.e. long-term) performance effects, and in equilibrium both periods are perfectly separated. If actions are unobservable, in contrast, long-term effects of effort emerge. Importantly, observing of the agent's actions needs not to be beneficial to the principal as all long-term incentives are eliminated.

Based on the results on the trade-off between motivating first- and second-period effort we presented implications for performance measurement and information system design.

First, we analyzed the value of observing the agent's productivity for the agency. Observation of the productivity has two effects in our model: Firstly, the agent selects his second-period action based on the productivity and secondly, (in short-term contracts) the principal uses the information to fine-tune the second-period incentive weight. In short-term contracts with observable effort not reporting the productivity can never be of any value as both periods are perfectly separated and for the second-period problem it is always (weakly) optimal to observe the information. In long-term contracts and in short-term contracts with unobservable effort, however, the use of the observation by the principal and by the agent may distort firstperiod incentives in a way that it would be better not to observe the signal. In addition, in long-term contracts installing an information system that reports the agent's productivity may induce a costly uncontrollable random second-period effort.

Second, we interpreted our setting as a two-period construction contract and compared two accounting regimes of revenue recognition: the percentage of completion method and the completed contract method. The distinguishing feature is that under the percentage of completion method all benefits resulting from first-period effort are reported in the first-period measure while under the completed contract method they are recognized when the project is fully completed, at the end of period two. This difference is important as it crucially influences the trade-off of motivating early and late effort via changing the productivity vectors of the performance measures. We derived conditions for the dominance of one or the other method, depending on the value of the agent's actions.

\section{Appendix: Proofs}

\section{Proof of Lemma 1}

The principal's problem to determine the optimal long-term contract is given in program (3). By substituting all constraints into the objective function (the participation constraint must bind at the optimum) this problem can be simplified as

$$
\begin{aligned}
\max _{s_{1}, s_{2}} Z^{L} & =g_{11}\left(s_{1} v_{11}+s_{2} v_{21}\right)+g_{12} s_{1} v_{12} \\
& -\frac{1}{2}\left(s_{1} v_{11}+s_{2} v_{21}\right)^{2}-\frac{1}{2} s_{1}^{2} v_{12}^{2} \\
& +s_{2} E\left(\theta \gamma_{2}\right)-\frac{E\left(\theta^{2}\right) s_{2}^{2}}{2} .
\end{aligned}
$$

From

$$
\begin{aligned}
\frac{\partial Z^{L}}{\partial s_{1}} & =g_{11} v_{11}+g_{12} v_{12} \\
& -\left(s_{1} v_{11}+s_{2} v_{21}\right) v_{11}-s_{1} v_{12}^{2}=0 \\
\frac{\partial Z^{L}}{\partial s_{2}} & =g_{11} v_{21}+E\left(\theta \gamma_{2}\right) \\
& -\left(s_{1} v_{11}+s_{2} v_{21}\right) v_{21}-s_{2} E\left(\theta^{2}\right)=0
\end{aligned}
$$


we obtain the optimal incentive weights as

$$
\begin{aligned}
s_{1}^{*} & =\frac{v_{21}^{2} g_{12} v_{12}-v_{11} v_{21} E\left(\gamma_{2} \theta\right)}{E\left(\theta^{2}\right)\left(v_{11}^{2}+v_{12}^{2}\right)+v_{12}^{2} v_{21}^{2}} \\
& +\frac{E\left(\theta^{2}\right)\left(g_{11} v_{11}+g_{12} v_{12}\right)}{E\left(\theta^{2}\right)\left(v_{11}^{2}+v_{12}^{2}\right)+v_{12}^{2} v_{21}^{2}} \\
s_{2}^{*} & =\frac{E\left(\gamma_{2} \theta\right)\left(v_{11}^{2}+v_{12}^{2}\right)+v_{12}^{2} g_{11} v_{21}}{E\left(\theta^{2}\right)\left(v_{11}^{2}+v_{12}^{2}\right)+v_{12}^{2} v_{21}^{2}} \\
& -\frac{v_{21} v_{11} g_{12} v_{12}}{E\left(\theta^{2}\right)\left(v_{11}^{2}+v_{12}^{2}\right)+v_{12}^{2} v_{21}^{2}}
\end{aligned}
$$

and the principal's equilibrium surplus is (with $\left.\Pi^{L} \equiv Z^{L}\left(s_{1}^{*}, s_{2}^{*}\right)\right)$

$$
\begin{aligned}
\Pi^{L} & =\frac{v_{21}^{2} v_{12}^{2}\left(g_{11}^{2}+g_{12}^{2}\right)}{2\left[E\left(\theta^{2}\right)\left(v_{11}^{2}+v_{12}^{2}\right)+v_{12}^{2} v_{21}^{2}\right]} \\
& +\frac{E\left(\theta^{2}\right)\left(v_{12} g_{12}+g_{11} v_{11}\right)^{2}}{2\left[E\left(\theta^{2}\right)\left(v_{11}^{2}+v_{12}^{2}\right)+v_{12}^{2} v_{21}^{2}\right]} \\
& +\frac{2 E\left(\gamma_{2} \theta\right) v_{21}\left(g_{11} v_{12}^{2}-g_{12} v_{11} v_{12}\right)}{2\left[E\left(\theta^{2}\right)\left(v_{11}^{2}+v_{12}^{2}\right)+v_{12}^{2} v_{21}^{2}\right]} \\
& +\frac{E\left(\gamma_{2} \theta\right)^{2}\left(v_{12}^{2}+v_{11}^{2}\right)}{2\left[E\left(\theta^{2}\right)\left(v_{11}^{2}+v_{12}^{2}\right)+v_{12}^{2} v_{21}^{2}\right]} .
\end{aligned}
$$

\section{Proof of Lemma 2}

The optimization problem for the optimal secondperiod contract conditional on conjecture $\widehat{\mathbf{e}}_{1}$ is given by (4):

$$
\begin{aligned}
& \max _{F_{2}, s_{2}} E\left(\pi \mid \theta, \widehat{\mathbf{e}}_{1}\right)-F_{2}-s_{2} E\left(y_{2} \mid \theta, \widehat{\mathbf{e}}_{1}\right) \\
& \text { subject to } \\
& e_{2}(\theta)=s_{2} \theta \\
& E\left(F_{2}+s_{2} y_{2} \mid y_{1}, \theta, \widehat{\mathbf{e}}_{1}\right)-C_{2}\left(e_{2}(\theta)\right) \geq 0 .
\end{aligned}
$$

The objective function can be written as $g_{11} \widehat{e}_{11}+g_{12} \widehat{e}_{12}+E\left(\gamma_{2} \mid \theta\right) e_{2}(\theta)-F_{2}$ $-s_{2}\left(v_{21} \widehat{e}_{11}+\theta e_{2}(\theta)\right)$. Removing terms that do not influence the optimization and substituting the incentive constraint and the binding participation constraint

$F_{2}+s_{2}\left(v_{21} \widehat{e}_{11}+\theta e_{2}(\theta)\right)-\frac{e_{2}(\theta)^{2}}{2}=0$ into the objective function, the principal's objective function is reduced to

$$
\max _{s_{2}} s_{2} \theta E\left(\gamma_{2} \mid \theta\right)-\frac{s_{2}^{2} \theta^{2}}{2} .
$$

From the first-order condition $\theta E\left(\gamma_{2} \mid \theta\right)-s_{2} \theta^{2}=0$ we get $s_{2}^{s *}=\frac{E\left(\gamma_{2} \mid \theta\right)}{\theta}$.

Substituting $s_{2}^{s *}$ into the binding participation constraint and solving for $F_{2}$ yields $F_{2}^{s *}=-\frac{E\left(\gamma_{2} \mid \theta\right)}{\theta} v_{21} \widehat{e}_{11}-\frac{1}{2} E\left(\gamma_{2} \mid \theta\right)^{2}$.

\section{Proof of Lemma 3}

Given the optimal second-period contract conditional on $\widehat{\mathbf{e}}_{1}$ as defined in Lemma 2 the program to determine the optimal first-period contract is given by (7). By substituting the binding participation constraint into the principal's objective function we obtain

$$
\begin{aligned}
& \max _{s_{1}} Z^{S}=g_{11}\left(s_{1} v_{11}+E\left(s_{2}^{s *}\right) v_{21}\right) \\
& +g_{12} s_{1} v_{12}-\frac{1}{2}\left(s_{1} v_{11}+E\left(s_{2}^{s *}\right) v_{21}\right)^{2} \\
& -\frac{1}{2} s_{1}^{2} v_{12}^{2}+\frac{1}{2} E\left\{E\left(\gamma_{2} \mid \theta\right)^{2}\right\}
\end{aligned}
$$

with $E\left(s_{2}^{s *}\right)=E\left(\frac{\gamma_{2}}{\theta}\right)$. From the optimality condition

$\frac{\partial Z^{S}}{\partial s_{1}}=g_{11} v_{11}+g_{12} v_{12}-\left(s_{1} v_{11}+s_{2}^{s *} v_{21}\right) v_{11}-s_{1} v_{12}^{2}=$ 0 we obtain the optimal first-period incentive rate as

(12) $s_{1}^{s *}=\frac{g_{11} v_{11}+g_{12} v_{12}-E\left(\frac{\gamma_{2}}{\theta}\right) v_{21} v_{11}}{v_{11}^{2}+v_{12}^{2}}$.

Substituting $s_{1}^{s *}$ into (11) yields the following equilibrium surplus for the principal:

$$
\begin{aligned}
\Pi^{S} & =\frac{\left(g_{11} v_{11}+g_{12} v_{12}\right)^{2}}{2\left(v_{11}^{2}+v_{12}^{2}\right)} \\
& +\frac{2 E\left(\frac{\gamma_{2}}{\theta}\right) v_{21}\left(g_{11} v_{12}^{2}-g_{12} v_{12} v_{11}\right)}{2\left(v_{11}^{2}+v_{12}^{2}\right)} \\
& -\frac{v_{12}^{2} v_{21}^{2}\left\{E\left(\frac{\gamma_{2}}{\theta}\right)\right\}^{2}}{2\left(v_{11}^{2}+v_{12}^{2}\right)} \\
& +\frac{1}{2} E\left\{E\left(\gamma_{2} \mid \theta\right)^{2}\right\} .
\end{aligned}
$$

\section{Proof of Lemma 4}

Program (8) can be simplified to $\max _{s_{1}} g_{11} s_{1} v_{11}+g_{12} s_{1} v_{12}-\frac{\left(s_{1} v_{11}\right)^{2}}{2}-\frac{\left(s_{1} v_{12}\right)^{2}}{2}$. The optimal solution to this program is given by $s_{1}^{o *}=\frac{g_{11} v_{11}+g_{12} v_{12}}{v_{11}^{2}+v_{12}^{2}}$ and the principal's corresponding first-period equilibrium surplus is $Z_{1}^{o *}=\frac{\left(g_{11} v_{11}+g_{12} v_{12}\right)^{2}}{2\left(v_{11}^{2}+v_{12}^{2}\right)}$.

\section{Proof of Proposition 5}

a) From Corollary 3 we know that if the conditions of Proposition 1 and Proposition 2 apply simultaneously: $\Pi^{L}=\Pi^{S}=\Pi^{S o}$. The condition of Proposition 1 ensures that for the payoff and the incentives generated in period 1 it is immaterial whether or not $\theta$ is observed. The principal's 
surplus from period 2 is $\Pi_{2}=E\left(\gamma_{2} e_{2}\right)-E\left(e_{2}^{2}\right) / 2$ with $e_{2}=s_{2} \theta$ if $\theta$ is observable and $e_{2}=s_{2} E(\theta)$ if not. Given the condition in Proposition $2\left(s_{2}=c\right)$, $\Pi_{2}^{\text {obser. }}-\Pi_{2}^{\text {unobser. }}=\frac{c^{2}}{2} \operatorname{Var}(\theta)>0$.

b) In short-term contracts with observable effort the principal's equilibrium payoff according to Lemma 4 is $Z^{o *}=Z_{1}^{o *}+Z_{2}^{*}$, where $Z_{1}^{o *}$ is independent of any characteristics of the second-period and

$Z_{2}^{*}=E\left\{E\left(\gamma_{2} \mid \theta\right)^{2}\right\}=E\left(\gamma_{2}\right)^{2}+\operatorname{Var}\left(E\left(\gamma_{2} \mid \theta\right)\right)$. If $\theta$ is non-observable the principal's second period payoff is $Z_{2}^{*^{\prime}}=E\left(\gamma_{2}\right)^{2}$. Hence, the value of observing $\theta$ is $\operatorname{Var}\left(E\left(\gamma_{2} \mid \theta\right)\right) \geq 0$.

c) Assume the conditions of Proposition 1 and Proposition 2 do not apply simultaneously for the rest of the proof.

c1) The principal's equilibrium payoff $\Pi^{L}$ in longterm contracts with observable $\theta$ is given in Lemma 1:

$$
\begin{aligned}
\Pi^{L} & =\frac{v_{21}^{2} v_{12}^{2}\left(g_{11}^{2}+g_{12}^{2}\right)}{2\left[E\left(\theta^{2}\right)\left(v_{11}^{2}+v_{12}^{2}\right)+v_{12}^{2} v_{21}^{2}\right]} \\
& +\frac{E\left(\theta^{2}\right)\left(v_{12} g_{12}+g_{11} v_{11}\right)^{2}}{2\left[E\left(\theta^{2}\right)\left(v_{11}^{2}+v_{12}^{2}\right)+v_{12}^{2} v_{21}^{2}\right]} \\
& +\frac{2 E\left(\gamma_{2} \theta\right) v_{21}\left(g_{11} v_{12}^{2}-g_{12} v_{11} v_{12}\right)}{2\left[E\left(\theta^{2}\right)\left(v_{11}^{2}+v_{12}^{2}\right)+v_{12}^{2} v_{21}^{2}\right]} \\
& +\frac{E\left(\gamma_{2} \theta\right)^{2}\left(v_{12}^{2}+v_{11}^{2}\right)}{2\left[E\left(\theta^{2}\right)\left(v_{11}^{2}+v_{12}^{2}\right)+v_{12}^{2} v_{21}^{2}\right]} .
\end{aligned}
$$

Solving program (3) with $e_{2}=s_{2} E(\theta)$ instead of $e_{2}(\theta)=s_{2} \theta$ leads to the following payoff for unobservable $\theta$ :

$$
\begin{aligned}
\Pi^{L \prime} & =\frac{v_{21}^{2} v_{12}^{2}\left(g_{11}^{2}+g_{12}^{2}\right)}{2\left[E(\theta)^{2}\left(v_{11}^{2}+v_{12}^{2}\right)+v_{12}^{2} v_{21}^{2}\right]} \\
& +\frac{E(\theta)^{2}\left[\left(v_{12} g_{12}+g_{11} v_{11}\right)^{2}+g_{12}^{2} v_{12}^{2}\right]}{2\left[E(\theta)^{2}\left(v_{11}^{2}+v_{12}^{2}\right)+v_{12}^{2} v_{21}^{2}\right]} \\
& +\frac{E(\theta)^{2} v_{12}^{2} E\left(\gamma_{2}\right)^{2}}{2\left[E(\theta)^{2}\left(v_{11}^{2}+v_{12}^{2}\right)+v_{12}^{2} v_{21}^{2}\right]} \\
& +\frac{2 E\left(\gamma_{2}\right) E(\theta) v_{21}\left(g_{11} v_{12}^{2}-g_{12} v_{11} v_{12}\right)}{2\left[E(\theta)^{2}\left(v_{11}^{2}+v_{12}^{2}\right)+v_{12}^{2} v_{21}^{2}\right]}
\end{aligned}
$$

If $\theta$ and $\gamma_{2}$ are independent we have $E\left(\theta \gamma_{2}\right)=$ $E(\theta) E\left(\gamma_{2}\right)$ in $\Pi^{L}$. Then the difference $\Pi^{L}-\Pi^{L^{\prime}}$ is given by

$$
\Pi^{L}-\Pi^{L^{\prime}}=-\frac{\operatorname{Var}(\theta)\left(E(\theta) E\left(\gamma_{2}\right)\left(v_{11}^{2}+v_{12}^{2}\right)+v_{12}^{2} g_{11} v_{21}-v_{21} v_{11} g_{12} v_{12}\right)^{2}}{2\left(E\left(\theta^{2}\right)\left(v_{11}^{2}+v_{12}^{2}\right)+v_{12}^{2} v_{21}^{2}\right)\left(E(\theta)^{2}\left(v_{11}^{2}+v_{12}^{2}\right)+v_{12}^{2} v_{21}^{2}\right)} \leq 0
$$

c2) In Lemma 3 the principal's surplus in shortterm contracts with unobservable effort is given by

$$
\begin{aligned}
\Pi^{S} & =\frac{\left(g_{11} v_{11}+g_{12} v_{12}\right)^{2}}{2\left(v_{11}^{2}+v_{12}^{2}\right)} \\
& +\frac{2 E\left(\frac{\gamma_{2}}{\theta}\right) v_{21}\left(g_{11} v_{12}^{2}-g_{12} v_{12} v_{11}\right)}{2\left(v_{11}^{2}+v_{12}^{2}\right)} \\
& -\frac{v_{12}^{2} v_{21}^{2}\left\{E\left(\frac{\gamma_{2}}{\theta}\right)\right\}^{2}}{2\left(v_{11}^{2}+v_{12}^{2}\right)}+\frac{1}{2} E\left\{E\left(\gamma_{2} \mid \theta\right)^{2}\right\}
\end{aligned}
$$

If $\theta$ will not be reported the corresponding surplus is

$$
\begin{aligned}
\Pi^{S^{\prime}} & =\frac{\left(g_{11} v_{11}+g_{12} v_{12}\right)^{2}}{2\left(v_{11}^{2}+v_{12}^{2}\right)} \\
& +\frac{2 \frac{E\left(\gamma_{2}\right)}{E(\theta)} v_{21}\left(g_{11} v_{12}^{2}-g_{12} v_{12} v_{11}\right)}{2\left(v_{11}^{2}+v_{12}^{2}\right)} \\
& -\frac{v_{12}^{2} v_{21}^{2}\left\{\frac{E\left(\gamma_{2}\right)}{E(\theta)}\right\}^{2}}{2\left(v_{11}^{2}+v_{12}^{2}\right)}+\frac{1}{2} E\left(\gamma_{2}\right)^{2}
\end{aligned}
$$

Stochastic independence of $\theta$ and $\gamma_{2}$ yields

$$
\begin{aligned}
& \Pi^{S}-\Pi^{S \prime}=\frac{2 v_{21}\left(g_{11} v_{12}^{2}-g_{12} v_{12} v_{11}\right) E\left(\gamma_{2}\right)\left[E\left(\frac{1}{\partial}\right)-\frac{1}{E(\theta)}\right]}{2\left(v_{11}^{2}+v_{12}^{2}\right)} \\
& -\frac{v_{12}^{2} v_{21}^{2} E\left(\gamma_{2}\right)^{2}\left[E\left(\frac{1}{\theta}\right)^{2}-\frac{1}{E(\theta)^{2}}\right]}{2\left(v_{11}^{2}+v_{12}^{2}\right)} \\
& =\frac{v_{21} v_{12} 2\left(g_{11} v_{12}-g_{12} v_{11}\right) E\left(\gamma_{2}\right)\left[E\left(\frac{1}{\partial}\right)-\frac{1}{E(\theta)}\right]}{2\left(v_{11}^{2}+v_{12}^{2}\right)} \\
& -\frac{v_{12}^{2} v_{21}^{2} E\left(\gamma_{2}\right)^{2}\left[E\left(\frac{1}{\partial}\right)^{2}-\frac{1}{E(\theta)^{2}}\right]}{2\left(v_{11}^{2}+v_{12}^{2}\right)}
\end{aligned}
$$

From Jensen's inequality that $E\left(\frac{1}{\theta}\right)-\frac{1}{E(\theta)}>$ 0 such that both brackets [.] are positive. For $g_{11} / g_{12}<v_{11} / v_{12} \Pi^{S}-\Pi^{S \prime}$ is always negative.

\section{Proof of Proposition 6}

The principal's surpluses: Substituting $v_{11}=(v+a)$ and $v_{21}=0$ for the percentage of completion method $(P C)$ and $v_{11}=v$ and $v_{21}=a$ for the completed contract method $(C C)$ into the principal's surplus functions given in Lemma 1, Lemma 3 , and Lemma 4, we obtain the following equilibrium payoffs 


$$
\begin{aligned}
& \Pi_{P C}^{L}=\frac{E\left(\theta^{2}\right)\left(v_{12} g_{12}+g_{11}(v+a)\right)^{2}}{2\left[E\left(\theta^{2}\right)\left((v+a)^{2}+v_{12}^{2}\right)\right]} \\
& +\frac{E\left(\gamma_{2} \theta\right)^{2}\left(v_{12}^{2}+(v+a)^{2}\right)}{2\left[E\left(\theta^{2}\right)\left((v+a)^{2}+v_{12}^{2}\right)\right]} \\
& \Pi_{C C}^{L}=\frac{a^{2} v_{12}^{2}\left(g_{11}^{2}+g_{12}^{2}\right)+E\left(\theta^{2}\right)\left(a g_{12}+g_{11} v\right)^{2}}{2\left[E\left(\theta^{2}\right)\left(v^{2}+v_{12}^{2}\right)+v_{12}^{2} a^{2}\right]} \\
& +\frac{2 E\left(\gamma_{2} \theta\right) a\left(g_{11} v_{12}^{2}-g_{12} v v_{12}\right)}{2\left[E\left(\theta^{2}\right)\left(v^{2}+v_{12}^{2}\right)+v_{12}^{2} a^{2}\right]} \\
& +\frac{E\left(\gamma_{2} \theta\right)^{2}\left(v_{12}^{2}+v^{2}\right)}{2\left[E\left(\theta^{2}\right)\left(v^{2}+v_{12}^{2}\right)+v_{12}^{2} a^{2}\right]} \\
& \Pi_{P C}^{S}=\frac{\left(g_{11}(v+a)+g_{12} v_{12}\right)^{2}}{2\left((v+a)^{2}+v_{12}^{2}\right)} \\
& +\frac{1}{2} E\left\{E\left(\gamma_{2} \mid \theta\right)^{2}\right\} \\
& \Pi_{C C}^{S}=\frac{g_{11}^{2} v^{2}+2 g_{11} v g_{12} v_{12}+g_{12}^{2} v_{12}^{2}}{2\left(v^{2}+v_{12}^{2}\right)} \\
& +\frac{2 E\left(\frac{\gamma_{2}}{\theta}\right) a\left(g_{11} v_{12}^{2}-v g_{12} v_{12}\right)}{2\left(v^{2}+v_{12}^{2}\right)} \\
& -\frac{v_{12}^{2} a^{2} E\left(\frac{\gamma_{2}}{\theta}\right)^{2}}{2\left(v^{2}+v_{12}^{2}\right)} \\
& +\frac{1}{2} E\left\{E\left(\gamma_{2} \mid \theta\right)^{2}\right\}
\end{aligned}
$$$$
\Pi_{P C}^{S o}=\frac{\left(g_{11}(v+a)+g_{12} v_{12}\right)^{2}}{2\left((v+a)^{2}+v_{12}^{2}\right)}+\frac{1}{2} E\left\{E\left(\gamma_{2} \mid \theta\right)^{2}\right\}
$$$$
\Pi_{C C}^{S o}=\frac{\left(g_{11} v+g_{12} v_{12}\right)^{2}}{2\left(v^{2}+v_{12}^{2}\right)}+\frac{1}{2} E\left\{E\left(\gamma_{2} \mid \theta\right)^{2}\right\} \text {. }
$$

Define $\Delta^{k} \equiv \Pi_{P C}^{k}-\Pi_{C C}^{k}, k=L, S, S o$.

a) Sketch: We can show that for each regime $k$ there exists a critical value $g_{12}^{k \prime}$ such that $\partial \Delta^{k} / \partial g_{12}<0$ if $g_{12}>g_{12}^{k \prime}$. Furthermore, $\lim _{g_{12} \rightarrow \infty} \Delta^{k}=-\infty$ for all $k$. Hence, for each regime there exists a critical value $g_{12}^{k}$ such that for all $g_{12}>g_{12}^{k}, \Delta^{k}<0$.

b) The ex-ante expected second-period action firm value productivity is $E\left(\gamma_{2}\right)$. In $\Pi_{(\cdot)}^{L}$ and $\Pi_{(\cdot)}^{S}$ we can write $E\left(\gamma_{2} \theta\right)=\operatorname{Cov}\left(\gamma_{2}, \theta\right)+E(\theta) E\left(\gamma_{2}\right)$ and $E\left(\frac{\gamma_{2}}{\theta}\right)=\operatorname{Cov}\left(\gamma_{2}, \frac{1}{\theta}\right)+E\left(\frac{1}{\theta}\right) E\left(\gamma_{2}\right)$, respectively. From

$\partial \Delta^{L} / \partial E\left(\gamma_{2}\right)=$

$\frac{-v_{12} a E(\theta)\left(E\left(\theta^{2}\right)\left(v_{12} g_{11}-v g_{12}\right)+a v_{12} \operatorname{Cov}\left(\gamma_{2}, \theta\right)+a v_{12} E(\theta) E\left(\gamma_{2}\right)\right)}{E\left(\theta^{2}\right)\left(z^{2}\left(v^{2}+v^{2}\right)+a v^{2}\right)}$

and $\partial \Delta^{S} / \partial E\left(\gamma_{2}\right)=$ $E\left(\theta^{2}\right)\left(z^{2}\left(v^{2}+v_{12}^{2}\right)+a v_{12}^{2}\right)$
$=$

$-\frac{E\left(\frac{1}{\theta}\right) a v_{12}\left(-\operatorname{Cov}\left(\frac{1}{\theta}, \gamma_{2}\right) a v_{12}-v_{12} a E\left(\frac{1}{\theta}\right) E\left(\gamma_{2}\right)+v_{12} g_{11}-v g_{12}\right)}{v^{2}+v_{12}^{2}}$ it follows that for each contracting regime $k=$ $L, S$ there exists a critical value $E\left(\gamma_{2}\right)^{k \prime}$ such that $\partial \Delta^{k} / \partial E\left(\gamma_{2}\right)>0$ if $E\left(\gamma_{2}\right)>E\left(\gamma_{2}\right)^{k \prime}$. Furthermore, $\lim _{E\left(\gamma_{2}\right) \rightarrow \infty} \Delta^{L}=+\infty$ and $\lim _{E\left(\gamma_{2}\right) \rightarrow \infty} \Delta^{S}=$ $+\infty$. Hence, there exists a critical value $E\left(\gamma_{2}\right)^{k}$ such that $\Delta^{k}>0$ for all $E\left(\gamma_{2}\right)>E\left(\gamma_{2}\right)^{k}$.

c) From

$\partial \Delta^{S o} / \partial g_{11}=\frac{\left\{g_{11}\left(2 v v_{12}+a v_{12}\right)-g_{12}\left(v^{2}+v_{12}^{2}+v a\right)\right\} a v_{12}}{\left(a^{2}+2 a v+v^{2}+v_{12}^{2}\right)\left(v^{2}+v_{12}^{2}\right)}$

and

$\partial \Delta^{S} / \partial g_{11}=\frac{a v_{12}}{\left(a^{2}+2 a v+v^{2}+v_{12}^{2}\right)\left(v^{2}+v_{12}^{2}\right)} \times$

$\left\{2 g_{11} v v_{12}+g_{12} v_{12}^{2}+g_{11} a v_{12}-g_{12} v^{2}-v g_{12} a\right.$

$\left.-E\left(\frac{\gamma_{2}}{\theta}\right) \times\left(a^{2} v_{12}+v_{12}^{3}+2 a v_{12} v+v_{12} v^{2}\right)\right\}$

it follows that for each $k=S, S o$ there exists $g_{11}^{k \prime}$ such that $\partial \Delta^{k} / \partial g_{11}>0$ for all $g_{11}>g_{11}^{k \prime}$. Furthermore, $\lim _{g_{11} \rightarrow \infty} \Delta^{S o}=+\infty$ and $\lim _{g_{11} \rightarrow \infty} \Delta^{S}=$ $+\infty$. Hence, there exists a critical value $g_{11}^{k}$ such that for all $g_{11}>g_{11}^{k}, \Delta^{k}>0$.

\section{Acknowlegdments}

I acknowledge helpful comments from two anonymous reviewers, Christian Riegler, Barbara Schöndube-Pirchegger, and from participants of the EAA annual conference 2007 in Lisbon and the VHB conference in Berlin 2008.

\section{References}

Arnegger, Martin and Christian Hofmann (2007): Periodisierung von Erfolgskomponenten zur Steuerung langfristiger Aufträge, Zeitschrift für Betriebswirtschaft, 77 (2): 115-139.

Arya, Anil, Jonathan C. Glover, and K. Sivaramakrishnan (1997): The Interaction Between Decision and Control Problems and the Value of Information, The Accounting Review, 72 (4): 561-574.

Baker, George P. (1992): Incentive Contracts and Performance Measurement, The Journal of Political Economy, $100(3): 598-614$.

Baker, George P. (2000): The Use of Performance Measures in Incentive Contracting, American Economic Review, 90 (2), Papers and Proceedings: 415-420.

Baron, David P. and David Besanko (1987): Commitment and Fairness in a Dynamic Regulatory Relationship, The Review of Economic Studies, 54 (3): 413-436.

Bolton, Patrick (1990): Renegotiation and the dynamics 
of contract design, European Economic Review, 34 (2-3): 303-310.

Budde, Jörg (2007): Performance measure congruity and the balanced scorecard, Journal of Accounting Research, 45 (3): 515-539.

Bull, Clive (1987): The Existence of Self-Enforcing Implicit Contracts, The Quarterly Journal of Economics, 102 (1): 147-159.

Bushman, Robert M., Raffi J. Indjejikian, and Mark Penno (200o): Private Predecision Information, Performance Measure Congruity, and the Value of Delegation, Contemporary Accounting Research, 17 (4): 562-587.

Chiappori, Pierre-André, Ines Macho, Patrick Rey, and Bernard Salanie (1994): Repeated moral hazard: The role of memory, commitment, and the access to credit markets, European Economic Review, 38 (8): 15271553.

Christensen, Peter O., Joel S. Demski, and Hans Frimor (2002): Accounting Policies in Agencies with Moral Hazard and Renegotiation, Journal of Accounting Research, 40 (4): 1071-1090.

Christensen, Peter O., Gerald Feltham, and Florin Şabac (2003): Dynamic Incentives and Responsibility Accounting: A Comment, Journal of Accounting and Economics, 35 (3): 423-436.

Christensen, Peter O., Gerald Feltham, and Florin Şabac (2005): A contracting perspective on earnings quality, Journal of Accounting and Economics, 39 (2): 265-294.

Christensen, Peter O. and Gerald Feltham (2005): Economics of Accounting, Vol.II: Performance Evaluation, Springer: New York.

Christensen, John A. and Joel S. Demski (2003): Accounting Theory: An Information Content Perspective, McGraw-Hill: New York.

Datar, Srikant, Susan Cohen Kulp, and Richard A. Lambert (2001): Balancing Performance Measures, Journal of Accounting Research, 39 (1): 75-92.

Demski, Joel. S. (1988): Economic Analysis of Information and Contracts, in: Feltham, Gerald A., Amin H. Amershi, and William T. Ziemba (eds.): Essays in Honor of John E. Butterworth, Kluwer, Boston, 373-408.

Demski, Joel S. and Hans Frimor (1999): Performance Measure Garbling under Renegotiation in Multi-Period Agencies, Journal of Accounting Research, 37 (Supplement): 187-214.

Dutta, Sunil and Stefan Reichelstein (2003): Leading Indicator Variables, Performance Measurement, and Long-Term Versus Short-Term Contracts, Journal of Accounting Research, 41 (5): 837-866.

Feltham, Gerald and Jim Xie (1994): Performance Measure Congruity and Diversity in Multi-Task Principal/Agent Relations, The Accounting Review, 69 (3): 429-453.
Feltham, Gerald, Raffi Indjejikian, and Dhananjay Nanda (2006): Dynamic incentives and dual-purpose accounting, Journal of Accounting and Economics, 42 (3): 417-437.

Fudenberg, Drew and Jean Tirole (1990): Moral Hazard and Renegotiation in Agency Contracts, Econometrica, 58 (6): 1279-1319.

Fudenberg, Drew, Bengt Holmström, and Paul Milgrom (1990): Short-Term Contracts and Long-Term Agency Relationships, Journal of Economic Theory, 51 (1): 1-31.

Gigler, Frank B. and Thomas Hemmer (2004): On the Value of Transparency in Agencies with Renegotiation, Journal of Accounting Research, 42 (5): 871-893.

Hermalin, Benjamin E. and Michael L. Katz (1991): Moral Hazard and Verifiability: The Effects of Renegotiation in Agency, Econometrica, 59 (6): 1735-1753.

Hofmann, Christian (2005): Gestaltung von Erfolgsrechnungen zur Steuerung langfristiger Projekte, Zeitschrift für betriebswirtschaftliche Forschung, 57 (12): 689-716.

Holmström, Bengt (1979): Moral hazard and observability, The Bell Journal of Economics, 10 (1): 74-91.

Holmström, Bengt and Paul Milgrom (1991): MultiTask Principal-Agent Analyses: Incentive Contracts, Asset Ownership, and Job Design, Journal of Law, Economics and Organization, 7 special issue: $24-52$.

Indjejikian, Raffi and Dhananjay Nanda (1999): Dynamic Incentives and Responsibility Accounting, Journal of Accounting and Economics, 27 (2): 177-201.

Indjejikian, Raffi and Dhananjay Nanda (2003): Reply to: dynamic incentives and responsibility accounting: a comment, Journal of Accounting and Economics, 35 (3): 437-441.

Kopel, Michael (1998): Zur verzerrten Performancemessung in Agency-Modellen, Zeitschrift für betriebswirtschaftliche Forschung, 50 (6): 531-550.

Kwon, Young K. (1989): Accrual Versus Cash-Basis Accounting Methods: An Agency-Theoretic Comparison, Journal of Accounting and Public Policy, 8 (4): 267-281.

Lambert, Richard A. (1983): Long-term contracts and moral hazard, The Bell Journal of Economics, 14 (2): 441-452.

Lambert, Richard A. (2001): Contracting Theory and Accounting, Journal of Accounting and Economics, 32 (1-3): 3-87.

Maskin, Eric (1999): Nash Equilibrium and Welfare Optimality, Review of Economic Studies, 66 (1): 39-56.

Meyer, Margaret A. and John Vickers (1997): Performance Comparisons and Dynamic Incentives, Journal of Political Economy, 105 (3): 547-581.

Meyer, Margaret A. (1995): Cooperation and competition in organizations: A dynamic perspective, European Economic Review, 39 (3-4): 709-722. 
Moore, John and Rafael Repullo (1988): SubgamePerfect Implementation, Econometrica, 56 (5): 11911220.

Reichelstein, Stefan (2000): Providing Managerial Incentives: Cash Flows versus Accrual Accounting, Journal of Accounting Research, 38 (2): 243-269.

Şabac, Florin (2007): Dynamic Agency with Renegotiation and Managerial Tenure, Management Science, 53 (5), 849-864.

Schöndube, Jens Robert (2005): Informationsgehalt und Performancemaß-Manipulation in einer Agency-Beziehung mit Nachverhandlungsmöglichkeit, Zeitschrift für Betriebswirtschaft, 75 (3): 219-246.

Sliwka, Dirk (2002): On the Use of Nonfinancial Performance Measures in Management Compensation, Journal of Economics and Management Strategy, 11 (3), 487-511.

Wagenhofer, Alfred (2003): Accrual-based compensation, depreciation and investment decisions, European Accounting Review, 12 (2), 287-309.

\section{Biography}

Jens Robert Schöndube is Junior Professor of Managerial Accounting at the Otto-von-GuerickeUniversity Magdeburg since April 2007. He graduated in business administration and received his doctoral degree in 2006 (University of Magdeburg). His research interests include dynamic agency models, corporate governance, and auction theory. 